\title{
EL CAMBIO DE LOS USOS AGRARIOS DEL SUELO EN EL ACTUAL ÁMBITO METROPOLITANO DE BARCELONA (DEL SIGLO XVIII A LA ACTUALIDAD) ${ }^{1}$
}

\author{
Valerià Paül Carril \\ Departamento de Xeografía, Universidade de Santiago de Compostela
}

\begin{abstract}
RESUMEN
Se plantea un análisis en profundidad del cambio de los usos agrarios del suelo en el ámbito territorial de la actual región metropolitana de Barcelona desde principios del siglo XVIII hasta el momento actual. El artículo se basa en un estudio minucioso de cinco fuentes de datos a escala municipal, correspondientes a distintos cortes temporales. Se lleva a cabo una discusión de los métodos utilizados para obtener estos datos y para asegurar su coherencia. Los resultados del trabajado explican las variaciones temporales y espaciales de los usos agrarios del suelo y se ponen en relación con el marco teórico del artículo. Las conclusiones sistematizan las tres grandes dinámicas que han motivado el cambio estudiado: la inserción de la agricultura regional en marcos geoeconómicos amplios, la conformación en el área de estudio de una verdadera agricultura periurbana y la influencia desigual del fenómeno urbanizador.
\end{abstract}

Palabras clave: usos agrarios del suelo, modelo de von Thünen, agricultura periurbana, especialización agraria, urbanización, región metropolitana de Barcelona.

\begin{abstract}
This paper will present an in-depth examination of agricultural land-use change in the area of the current day metropolitan region of Barcelona since the early $18^{\text {th }}$ century. It is based on a meticulous study of five data sources at municipal scale over different time moments. The manuscript will discuss the methodologies used to obtain this data and to ensure its consistency. The results will explain the temporal and spatial differences of the agricultural land-uses and will be discussed in light of the theoretical context. The paper concludes by identifying the key triggers for change: the inclusion of regional agriculture
\end{abstract}

1 Este artículo se inscribe en los proyectos de investigación «Las unidades básicas de paisaje agrario de España: identificación, delimitación, caracterización y valoración» (CSO2009-12225-C05-03, IP Joan Tort) y «Sistema de indicadores para el análisis de las dinámicas urbanas y metropolitanas en España a comienzos del siglo XXI» (CSO2010-16298, IP Rubén C. Lois), ambos financiados por el Ministerio de Ciencia e Innovación (Gobierno de España). 
into wider geo-economic contexts, the emergence of true peri-urban agriculture in the case study area and the uneven influence of the urban encroachment.

Key words: agricultural land-uses, von Thünen model, peri-urban agriculture, agricultural specialisation, urban development, metropolitan region of Barcelona.

\section{Introducción: los usos agrarios del suelo ${ }^{2}$ en las proximidades urbanas}

Existe un consenso amplio sobre el hecho de que la agricultura localizada cerca de las ciudades presenta características distintivas que la diferencian de aquella que se encuentra apartada de las mismas (Bryant y Johnston, 1992; Donadieu, 1998; Paül y McKenzie, 2010). El economista alemán Johann Heinrich von Thünen (1785-1850) es considerado como el primer teorizador de las peculiaridades de la agricultura próxima a las zonas urbanas. Dicho autor propuso en su libro El estado aislado (1826) la idea de que la distancia respecto al mercado urbano es la principal variable a la hora de escoger qué cultivo y qué intensidad se debe aplicar a una parcela agraria dada (Chisholm, 1962; Haggett et al., 1977; Grigg, 1995; Robinson, 2004). Según este criterio, es esperable que los cultivos más perecederos e intensivos - en la época de von Thünen, intensivos en términos de trabajo - se encuentren en los alrededores de las ciudades, lo que distingue los ámbitos agrarios próximos a zonas urbanas de los más alejados.

El modelo de von Thünen se manifiesta espacialmente en la presencia de franjas hortofrutícolas o productoras de leche que acostumbran a rodear a las zonas urbanas. La mayoría de los manuales existentes de geografía rural o agraria, tanto en la tradición anglosajona (por ejemplo, Robinson, 2004) como en la francesa (por ejemplo, Chaléard y Charvet, 2004), detectan y transmiten este patrón de producción hortícola o lechera próxima a la ciudad. ${ }^{3}$ Los ejemplos son múltiples y con variantes; así, póngase por caso, no siempre se da el cinturón lechero, pero abundan las franjas hortícolas periurbanas. Por citar algunas ciudades concretas, se pueden referenciar Buenos Aires (Barros, 2006: 330-331), París y Argel (Chaléard y Charvet, 2004: 122-124), Brisbane (Choy et al., 2008: 19-20) o las ciudades asiáticas Osaka y Busan (Araki, 2005: 47-51). Aunque se ha discutido enormemente sobre la actual validez del modelo thüniano (Garcia Ramon, 1976), entre otros motivos por la revolución de los transportes o la aparición y extensión de la tecnología del frío y de la agroindustria (productos envasados, precocinados, etc.), aún hoy en día se siguen planteando investigaciones que parten de sus supuestos y los aplican a regiones urbanas - por

2 A pesar de que en los últimos años se ha tendido a proponer una distinción estricta entre los conceptos de uso y cobertura del suelo (Boada y Saurí, 2002), aquí empleamos ambos de forma indiferenciada, aunque preferimos el primero por su uso tradicional en geografía agraria como término que se refiere al cultivo, es decir, a la utilización agraria del territorio (Meynier, 1959; Majoral, 1979; López Ontiveros, 2003). En lo que respecta a la distinción entre las expresiones agrario y agrícola, optamos por la primera, dada su mayor amplitud, englobando a la ganadería, que será aludida aquí con asiduidad.

3 Estas y otras consideraciones sobre usos del suelo agrarios alrededor de la ciudad que se harán en lo sucesivo omiten las relaciones entre agricultura, medio natural y contexto cultural. Esta preterición se debe a que la teorización sobre la agricultura próxima a la ciudad ha puesto el énfasis en los aspectos estrictamente económicos y, en términos generales, ha olvidado los factores naturales o culturales. Von Thünen, de hecho, modelizó partiendo de la base de que las condiciones de fertilidad del suelo eran homogéneas. En lo referente a la cultura, la presencia frecuentemente aludida de un cinturón de explotaciones lecheras alrededor de la ciudad suele olvidar el hecho de que el consumo de leche es reciente y responde a determinados modelos socioculturales (Ràfols, 2000; Cussó y Garrabou, 2006). De este modo, la correlación entre usos del suelo tipo forraje para ganado urbano, por un lado, y proximidad urbana, por otro, no es incontrovertible. Veremos el caso de Barcelona en este artículo. 
poner dos casos recientes, para el área de Moscú, Ioffe y Nefedova (2001); para las áreas metropolitanas de Estados Unidos, Thomas y Howell (2003).

El modelo thüniano fue especialmente citado y discutido durante el dominio de la geografía teorético-cuantitativa, sensu lato entre las décadas de 1950 y 1980 . Por aquel entonces emergieron con fuerza determinadas críticas vinculadas a una cuestión omitida por von Thünen, pero que ahora ya se asume como determinante en la agricultura en contacto con la ciudad: la urbanización (Bryant y Johnston, 1992). En efecto, el avance de la mancha urbana provoca la pérdida física de la agricultura, lo que constituye sin duda un cambio mayúsculo en términos de usos del suelo. Desde el punto de vista de la investigación, esta constatación ha dado lugar a toda una «narrativa negativa» sobre la agricultura próxima a las ciudades, que en lo fundamental se dedica a la cuantificación y explicación del patrón de consumo urbano de tierras agrarias (Benfield et al., 1999; Boismenu, 2004). En paralelo, existe la posibilidad, observada desde hace décadas, de un progresivo desplazamiento en el espacio de las actividades agrarias más intensivas, empujadas por la expansión urbana, de modo que la agricultura originalmente alejada de una determinada ciudad se intensifica a medida que ésta se acerca, lo que suele conllevar dinámicas de cambio evidentes en los usos agrarios del suelo de estos ámbitos (Bryant y Johnston, 1992; Chaléard y Charvet, 2004).

Los postulados thünianos tampoco concebían que, en contra de la lógica espacial del aumento constante de la intensificación agraria cerca de la ciudad (para aprovechar la proximidad al mercado urbano o competir ante los usos urbanos), pueda producirse un abandono de la agricultura por rentas expectantes o especulativas. En este sentido, Juillard (1961) fue seguramente el primer autor que sistematizó un concepto que ha tenido mucho éxito en la literatura sobre agricultura bajo influencia urbana, el de baldío social. ${ }^{4}$ De hecho, una de las teorizaciones subsiguientes a von Thünen es la de la anticipación de Sinclair (1967), que en lo fundamental conceptualiza la posibilidad de una agricultura no intensiva e, incluso, de campos abandonados cerca de la ciudad dadas las expectativas urbanísticas que se generan por la proximidad del frente urbano.

Tampoco von Thünen a principios del ochocientos podía prever la influencia que la ordenación territorial o el planeamiento urbanístico ejercen en los ámbitos cerca de las ciudades, y en particular en sus usos agrarios del suelo. Ya en la década de 1970 se plantearon determinados modelos de usos e intensidades agrarios teniendo en cuenta la presencia de estrategias de ordenación como los greenbelts (anillos verdes) no urbanizables alrededor de las ciudades (Bryant et al., 1982). En el contexto actual se han descrito varias implicaciones de la ordenación en los usos del suelo agrarios próximos a la ciudad. De entrada, una situación habitual consiste en su consideración como suelo urbanizable, lo que puede acarrear el abandono de la actividad agraria y la aparición del baldío social referido, antes de que se produzca físicamente la urbanización. Otra posibilidad es su protección, lo que aparentemente garantiza la continuidad de los usos preexistentes, aunque no siempre ello es así. Finalmente, se detecta un creciente rol de la administración ambiental en la toma de decisiones; ésta suele privilegiar los usos forestales a los agrarios, considerados estos segundos más lesivos desde el punto de vista del medio; todo ello puede conllevar en casos extremos planificar la substitución de usos agrarios por forestales u otros como lagunas, parques, etc. (Fleury y Donadieu, 1997; Goetgeluk et al., 2005; Paül, 2006, 2009).

Esta rápida revisión de literatura sobre los usos del suelo agrarios próximos a la ciudad no puede obviar la constatación generalizada en la bibliografía sobre la compleja diversidad de los conocidos como ámbitos periurbanos, es decir, los espacios situados en la periferia de

4 Esta es la traducción que propone Gómez Mendoza (1977) para el concepto. A veces se prefieren barbecho o yermo periurbanos, el primero con el matiz de un abandono no definitivo. En francés se suele hablar de friche d'attente (baldío en espera) y en inglés de idle o fallow lands (campos abandonados). 
la ciudad. En ellos los usos agrarios suelen aparecer intercalados con usos no estrictamente agrarios o, en su caso, agrarios pero no destinados a la producción comercial de alimentos (Bryant et al., 1982; Bryant y Johnston, 1992; Gallent y Andersson, 2007; Choy et al., 2008; Bomans et al., 2010; Gant et al., 2011). En este punto, las posibilidades son múltiples y van desde los huertos de ocio no profesionales - denominados en francés agriculture de loisir y en inglés hobby farming - hasta los prados cultivados para mantener caballos - el proceso conocido académicamente en estos momentos en Europa como horsification-, pasando por una amalgama de usos de difícil adscripción, que no son rurales ni plenamente urbanos: extracciones de áridos, vertederos, parcelaciones urbanísticas no consolidadas, etc. Todo ello genera un paisaje periurbano enormemente complejo - terrenos vagos e imprecisos en la concepción de Nogué (2003) —, donde en muchas ocasiones lo agrario es dominante (la matriz paisajística), pero salpicado de múltiples y diversas teselas. De todos modos, estos usos emergentes suelen ser difícilmente aprehensibles a través de estadísticas generales o de fotografías aéreas o imágenes de satélite a pequeña escala (Gant et al., 2011).

Hasta aquí nos hemos referido a los usos agrarios ubicados en las inmediaciones de la ciudad sin denominar de forma específica la agricultura en cuestión. A pesar de la amplia literatura disponible, no hay un acuerdo conceptual común. En la tradición anglosajona, se ha preferido el concepto agriculture in the rural-urban fringe (agricultura en la franja rural-urbana), mientras que en la francesa se ha utilizado más bien agriculture périurbaine (agricultura periurbana), denominación, esta última, que se ha generalizado en lengua española y por parte de la FAO (Drescher, 2001).

La noción de franja pone más el énfasis en la idea de la transición entre lo rural y lo urbano, con una cierta autonomía respecto a ambos, mientras que el prefijo peri parte de una subordinación a la ciudad. La cuestión más compleja en relación con este tipo de agricultura es siempre su alcance espacial. Partiendo de la idea de sumisión respecto a un centro urbano, la OCDE (1979) propone que la agricultura periurbana sea aquella que se encuentra hasta unos $20 \mathrm{~km}$ de radio desde el entorno de un núcleo urbano. Audirac (1999) entiende que la franja rural-urbana se extiende hasta $15 \mathrm{~km}$ más allá de la ciudad. Houston (2005), como tantos otros autores, opta por considerar que la agricultura periurbana es la localizada dentro de las áreas metropolitanas, de geometría variable y dependientes en buena medida de las dinámicas de movilidad obligada asociadas a ciudades centrales. Tal y como se verá en el próximo punto, aquí optamos por una delimitación operativa y, de forma congruente con la denominación más extendida, nos referiremos a los usos del suelo agrarios que siguen el modelo thüniano como propios de la agricultura periurbana.

Efectuadas estas consideraciones introductorias que enmarcan teóricamente el artículo, corresponde indicar que el objetivo del mismo es el análisis del cambio de usos agrarios del suelo de la actual región metropolitana de Barcelona desde el siglo XVIII hasta la actualidad. El porqué de este intervalo temporal, así como el alcance del ámbito de estudio, se especifican en el próximo apartado de carácter metodológico (apartado 2). El resto de la contribución se estructura mediante lecturas temporales basadas en datos de distintos momentos del período de referencia. Primero, tres apartados se dedican a las estadísticas obtenidas para principios del siglo XVIII (apartado 3), mediados del siglo XIX (4) y mediados del siglo Xx (5). Después, nos centramos en el último medio siglo, en dos epígrafes, uno sobre la diversidad de tipos de usos agrarios (apartado 6) y otro sobre la disminución global de la superficie agraria (7). Las conclusiones finales (apartado 8) sistematizan los cambios de usos del suelo observados mediante tres grandes dinámicas, a la par que se ponen en relación con las aportaciones teóricas revisadas en el apartado 1. 


\section{2. Ámbito de estudio y consideraciones metodológicas}

Este artículo parte de una tesis inédita que contiene un capítulo específico sobre los usos agrarios del suelo de la actual región metropolitana de Barcelona (Paül, 2006), cuyos principales contenidos se sistematizan en los apartados empíricos del presente trabajo. De ello se derivan de entrada dos implicaciones metodológicamente relevantes. Por un lado, el ámbito de estudio. Por otro, el nivel de resolución de los datos.

En lo que se refiere al ámbito de estudio, optamos por escoger lo que actualmente se conoce como región metropolitana de Barcelona, es decir, las siete comarcas representadas en la figura 1, con un total de 5.012.961 habitantes (en 2010,67\% de Catalunya) en $3.241 \mathrm{~km}^{2}$ (10\% de Catalunya). Esta delimitación territorial fue propuesta por vez primera en la década de 1960 en el conocido como «plan director» aprobado en 1968, aunque sin consecuencias prácticas. En 1995, este ámbito es confirmado por ley como el área para la planificación territorial metropolitana y desde entonces ha venido actuando como demarcación de una futura veguería, esto es, el nivel de gobierno supralocal que según el Estatut de 2006 (art. 91.3) debe substituir a la provincia. ${ }^{5}$

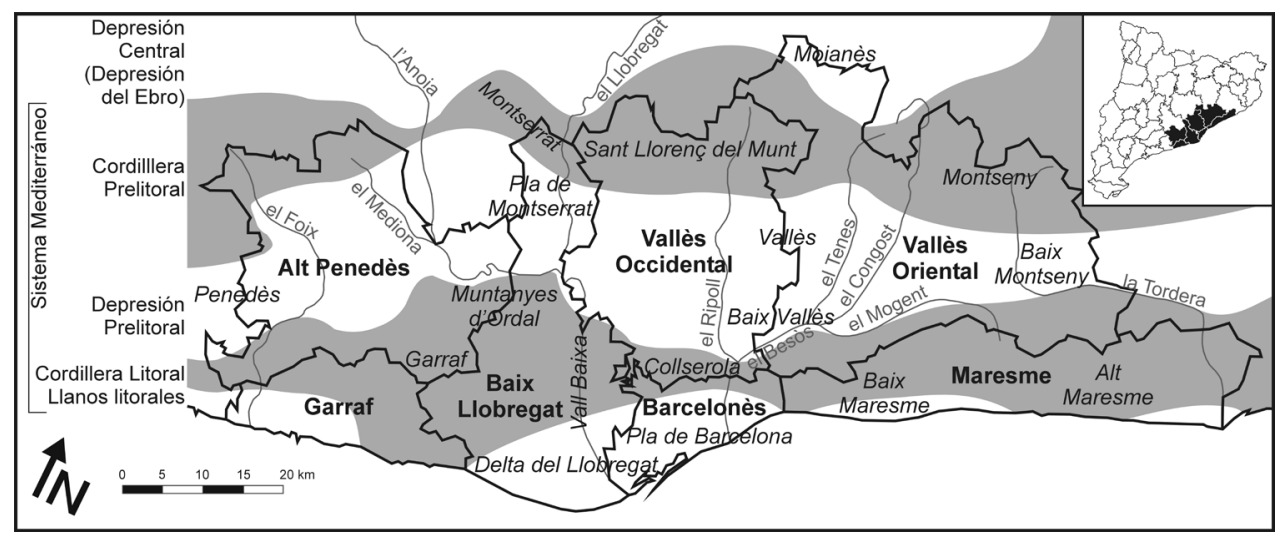

FIGURA 1. División comarcal, grandes unidades de relieve y toponimia mayor escogida de la región de estudio.

Elaboración propia.

La delimitación escogida comporta utilizar una división territorial contemporánea en períodos anteriores, de modo que el trabajo efectuado para los siglos XVIII, XIX y buena

5 Se estipula que el ámbito metropolitano es una demarcación de planificación mediante la Llei 1/1995, del 16 de març, per la qual s'aprova el Pla territorial general de Catalunya. Con posterioridad al Estatut de 2006, el art. 9.b de la ley de veguerías (Llei 30/2010, del 3 d'agost, de vegueries) convierte esta demarcación ordenadora en veguería. No obstante, la entrada en vigor de las veguerías ha sido aplazada sine die por una ley posterior (Llei 4/2011, del 8 de juny, de modificació de la Llei 30/2010, del 3 d'agost, de vegueries). También cabe mencionar que la Llei $1 / 1995$ ha sido recientemente reformada para desagregar las comarcas del Garraf y el Alt Penedès del ámbito de planificación metropolitana y constituir, junto a otras, el ámbito del Penedès (Llei 23/2010, del 22 de juliol, de modificació de la Llei 1/1995 i de la Llei 23/1983 per a fixar l'àmbit de planificació territorial del Penedès). Esta medida puede comportar una eventual reconfiguración del mapa metropolitano, pero en todo caso no se ha trasladado a la legislación específica sobre veguerías, de modo que la de Barcelona -aun sin trascendencia práctica - sigue incluyendo a las dos comarcas mencionadas. En otro orden de cosas, no debe confundirse este nivel metropolitano extenso con el área metropolitana en sentido estricto implantada recientemente (Llei 31/2010, del 3 d'agost, de l'Àrea Metropolitana de Barcelona), de alcance territorial reducido. 
parte del xx puede entenderse como geográficamente incoherente en la medida en que la región sólo se configura y delimita en el último medio siglo. Sin embargo, se opta por usarla por tres motivos. En primer lugar, el ámbito de estudio satisface ampliamente los criterios numéricos de delimitación de la agricultura periurbana señalados más arriba y de hecho casi coincide con el espacio metropolitano delimitado funcionalmente por el fenómeno de la movilidad obligada. En segundo lugar, el ámbito escogido plantea menos conflictos que otras opciones de delimitación de región de estudio ${ }^{6}$ y además es pertinente en una tesis dedicada centralmente a la ordenación territorial en la medida en que, desde 1995, es el ámbito del plan territorial correspondiente. Finalmente, si se realiza un estudio histórico de los usos del suelo es para entender la conformación y desarrollo de la agricultura periurbana de Barcelona y a priori no se debe prejuzgar su extensión, por lo que es prudente abarcar una región lo más amplia posible, a sabiendas de su extemporaneidad en el pasado.

En lo que atañe al nivel de resolución, por la naturaleza del ámbito de estudio, con un total de 164 municipios actualmente y casi 200 en el pasado, es imposible plantear un trabajo de más detalle que la escala municipal. Para determinadas cuestiones, trabajamos en su día con datos y mapas de mayor detalle que nos permitieron corroborar algunas dinámicas específicas, pero en términos generales investigamos con la planta municipal. Así pues, el método de trabajo básico ha consistido en confeccionar bases de datos de distintos momentos correspondientes a los municipios del actual conjunto metropolitano y, una vez estructuradas esas bases como una serie coherente, ver cómo han evolucionado los usos del suelo agrarios. Buscamos dos grandes tipos de cifras. Por un lado, su comportamiento global, en el sentido de si los usos del suelo agrario disminuyen o aumentan en superficie, dinámica que en parte supone ponerlos en relación con otros usos del suelo (urbanos y forestales, fundamentalmente). Por otro lado, su variación interna, es decir, los cambios de usos del suelo agrarios que se producen a tenor de las distintas orientaciones productivas.

Se presentan en este artículo los datos cuantitativos tratables estadísticamente y, por lo tanto, mapificables. De este modo, las informaciones cualitativas, ya sean de fuentes primarias - viajeros, cuestionarios, informes, etc. - o secundarias - en lo fundamental, bibliografía historiográfica-, se han utilizado aquí para entender los cambios que las estadísticas ponen de manifiesto, pero no como base del estudio propiamente dicho, de forma que no se referencian de forma sistemática. Los apartados empíricos del artículo giran alrededor de mapas que expresan los resultados de la serie estadística obtenida. Dichos mapas se comentan tanto de forma individual como en relación con los otros.

Partimos de la obviedad que en nuestro país los datos de este tipo suelen ser de difícil acceso, lo que implica un intenso esfuerzo investigador orientado a su obtención y elaboración. No es necesario incidir en el hecho perfectamente conocido de que están plagados de errores, omisiones, falta de coherencia, cambios de criterios y problemas de diversa índole que imposibilitan la comparación entre datos de diferentes fechas. Todo ello ya fue manifestado en su día por Majoral (1979) y el estado de la cuestión no ha mejorado demasiado. Nos sumamos a sus consideraciones cuando afirma: «[L]a alternativa a un problema que no es sólo nuestro (numerosos investigadores se quejan en diversos países, con fondos de estadísticas mucho mejores), es utilizarlos [los datos] como se hallan o dejar los trabajos en este sentido. Es por ello que, dando siempre un margen al error y a la duda, [...] decidimos a pesar de los inconvenientes, llevar adelante el trabajo, esperando que, en definitiva, si no del todo válidos, nuestros resultados, sean como mínimo aproximativos, y reflejen, en líneas generales, la realidad que estudiamos» (Majoral, 1979: 130-131).

6 Nel·lo (2001: 118) ha resumido la imposibilidad de delimitar la región metropolitana de Barcelona con una frase que juzgamos axiomática: «se trata de una controversia irresoluble de forma unívoca desde el punto de vista científico» (la traducción es nuestra). 
Para trabajar con garantías, cabe efectuar las siguientes consideraciones, algunas de las cuales actúan como prevenciones:

- Obviamos las fuentes (recientes) que se derivan de teledetección o de interpretación de fotografía aérea. Únicamente al final de este trabajo se ofrecerá una tabla elaborada con las mismas que nos valdrá para comparar con la dinámica global de la pérdida de suelos agrarios obtenida mediante nuestra serie, pero en términos generales se excluyen del estudio al ser incomparables con las estadísticas que hemos manejado.

- En el caso de las fuentes de baja fiabilidad, sobre todo en los siglos XVIII y XIX, hemos privilegiado el estudio de los porcentajes municipales de los distintos usos sobre las superficies exactas declaradas, altamente inexactas. Giralt (1950: 166) ya comentó que las cifras absolutas en CT1717 (tabla 1) son imprecisas, pero no obstante permiten apreciar las «tendencias dominantes».

- Aceptamos como válida la comparación entre distintas fuentes (véase la tabla 1). Ello induce a problemas metodológicos de calado, pero no hay otra forma de trabajar, dado que no existe una serie coherente de usos del suelo por municipios que se haya mantenido en el tiempo. De hecho, las series que perduran también adolecen de cambios metodológicos, por ejemplo entre los formularios 1T de 1973 o 2004, o los censos agrarios de 1982, 1989 y 1999.

- Derivado del punto anterior, reducimos el abanico de categorías existentes en cada fuente a una lista cerrada que intentamos identificar y cuantificar en todas las bases: cereales, hortalizas y flores, viñedos, cultivos forrajeros, olivares y frutales de clima templado. ${ }^{7}$ Este listado es aplicable a partir de AM1850 (tabla 1), ésta incluida. En caso de que el porcentaje de alguna de estas clases no supere el $40 \%$ (calculado respecto a las tierras labradas o cultivadas - véanse las explicaciones subsiguientes), ${ }^{8}$ clasificamos el municipio, según el caso, en herbáceos varios, leñosos varios o policultivos.

- Derivado también del antepenúltimo punto, y dados los problemas observados en la clasificación de superficies boscosas de distinto tipo, yermos, pastizales, barbechos, etc., hemos preferido trabajar con la categoría general de tierras cultivadas o labradas, evitando el total de la superficie agraria útil (SAU). Este procedimiento nos ha comportado una tarea de recálculo compleja, pero la inclusión de las superficies no agrícolas nos hubiera abocado a una indeterminación general de muchas comparaciones. Obviamente, la exclusión de los yermos o los barbechos nos impide cuantificar el baldío social aludido, pero estamos convencidos de que la detección del mismo sólo es posible mediante trabajo de campo (y no por estadísticas o fotografía aérea). ${ }^{9}$

7 En Molinero et al. (2004) se agrupan los frutales, a excepción de los cítricos, en frutales de clima templado (melocotoneros, cerezos, ciruelos, etc.) y frutos secos (almendros, avellanos, algarrobos, etc.). Los primeros son los que tienen o han tenido cierta presencia histórica en la región de Barcelona. Los segundos han actuado más bien de acompañantes, por lo que aquí no constituyen una categoría propia.

8 El umbral del $40 \%$ proviene de la técnica de representación cartográfica de predominio de usos del suelo agrarios a escala municipal diseñada por Roser Majoral y Dolores Sánchez Aguilera, aplicada con éxito en Majoral (2002) y ampliamente representada en Molinero et al. (2004), y que sin duda se basa en una profunda reflexión acumulada sobre cartografía de usos agrarios del suelo desde Majoral (1979). Esta propuesta cartográfica suele considerar dos intervalos de predominancia $(40-60 \%$ y $>60 \%)$, pero el formato de esta revista nos obliga a ceñirnos al uso principal $>40 \%$ de cada municipio.

9 Esta conclusión no se deriva únicamente de la investigación efectuada a través de fuentes estadísticas hasta 2006, sino también de la llevada a cabo los años 2007 y 2008, cuyos resultados no se ofrecen en este artículo por circunscribirse a un área concreta. Nos referimos a los convenios de colaboración entre el Parc Agrari del Baix Llobregat y el Institut d'Estudis Territorials para la elaboración, mediante trabajo de campo, de un mapa de coberturas del ámbito del parque agrario del Baix Llobregat en el marco del sistema de información geográfica del Parc Agrari SIGAT (Callau et al., 2008). 
Efectuadas estas puntualizaciones, pasamos a comentar brevemente las fuentes empleadas, incluyendo las precisiones oportunas. De entrada, en la tabla 1 las sistematizamos, aportando las siglas que en lo sucesivo utilizaremos. Es necesario advertir que en realidad a lo largo del artículo aparecerán mencionadas otras fuentes, en cuyo caso se harán las observaciones metodológicas necesarias.

Tabla 1

PRINCIPALES FUENTES ESTADÍSTICAS EMPLEADAS

\begin{tabular}{|l|l|l|l|}
\hline $\begin{array}{l}\text { Denominación de la } \\
\text { fuente y año (entre } \\
\text { paréntesis) }\end{array}$ & $\begin{array}{c}\text { Sigla em- } \\
\text { pleada }\end{array}$ & $\begin{array}{l}\text { Lugar de obtención o consulta } \\
\text { de la serie }\end{array}$ & $\begin{array}{c}\text { Recubrimiento espacial y tem- } \\
\text { poral }\end{array}$ \\
\hline $\begin{array}{l}\text { Catastro de José } \\
\text { Patiño ( 1717) }\end{array}$ & CT1717 & $\begin{array}{l}\text { Bibliografía local diver- } \\
\text { sa, pero sobre todo Giralt } \\
(1950) \text {, con una tabla para } \\
\text { todo el Penedès }\end{array}$ & $\begin{array}{l}\text { Incompleto espacialmente } \\
\text { años }\end{array}$ \\
\hline $\begin{array}{l}\text { Amillaramientos } \\
(1850-1865)\end{array}$ & AM1850 & $\begin{array}{l}\text { Consulta de todos los ami- } \\
\text { llaramientos municipales } \\
\text { en el Arxiu de la Corona } \\
\text { d'Aragó }\end{array}$ & $\begin{array}{l}\text { Completo espacialmente, } \\
\text { pero correspondiente a va- } \\
\text { rios años }\end{array}$ \\
\hline $\begin{array}{l}\text { Catastro de rústica } \\
(1955-1956)\end{array}$ & CT1955 & $\begin{array}{l}\text { Consulta de una tabla ela- } \\
\text { borada por Roser Majoral, } \\
\text { inédita }\end{array}$ & $\begin{array}{l}\text { Completo y correspondien- } \\
\text { te a dos años }\end{array}$ \\
\hline $\begin{array}{l}\text { Hojas 1T } \\
(1973)\end{array}$ & 1 T1973 & $\begin{array}{l}\text { Volumen II de la tesis doc- } \\
\text { toral de Roser Majoral } \\
(1979)\end{array}$ & $\begin{array}{l}\text { Completo y correspondien- } \\
\text { te a un año }\end{array}$ \\
\hline $\begin{array}{l}\text { Censo agrario } \\
(1999)\end{array}$ & CA1999 & $\begin{array}{l}\text { Internet<http://www.ides- } \\
\text { cat.cat> }\end{array}$ & $\begin{array}{l}\text { Completo y correspondien- } \\
\text { te a un año }\end{array}$ \\
\hline
\end{tabular}

Elaboración propia.

En lo que se refiere al primer catastro, se trata de la primera recaudación tributaria sistemática de carácter único aplicada a Catalunya después de la derrota de 1714 y de la Nueva Planta sancionada por Felipe v en 1715. Mediante una normativa publicada en 1716, José Patiño implanta el catastro como superintendente borbónico de Catalunya, basándolo entre otros criterios en los usos del suelo (Segura, 1988; Burgueño, 2007; Camarero, 2007). Llobet (1955a) considera que el grado de ocultación en este catastro es alto. Cierta o no esta ocultación, el catastro completo no se ha encontrado y por lo tanto sólo se dispone de fragmentos, en general municipales.

Sin embargo, Giralt (1950) localizó en el archivo notarial de Vilafranca este primer catastro correspondiente a la antigua veguería del Penedès y, por lo tanto, contamos con un tercio aproximadamente de la región de estudio cubierta. Por ser el documento del Penedès de 1717, hemos denominado la fuente CT1717. Le hemos añadido datos locales de trece municipios más localizados de forma aislada en bibliografía dispersa, pero que no siempre son de 1717, sino de fechas inmediatamente anteriores o posteriores: Llobet (1955a) ofrece datos para varios municipios del Maresme; Llobet (1968), para Granollers y Terrassa; Segura y Suau (1984), para Barcelona; Pinyot (1985), para Castellar; Pérez 
Molina (1990), para L'Hospitalet; y Planas (2007), para Cànoves y Martorelles. Probablemente existan los catastros de Patiño para todos los pueblos de Catalunya (Nadal et al., 2005), pero que sepamos de momento no han merecido una investigación sistemática. Hay que señalar, finalmente, que la planta municipal de entonces era distinta a la actual, lo que también sucede en el ochocientos, y que por lo tanto, la delimitación municipal representada en el mapa resultante (figura 2) es controvertida, aunque nos servimos profusamente de Burgueño y Lasso (2003).

Por lo que respecta a los amillaramientos, son directamente herederos de la reforma fiscal liberal del ministro Alejandro Mon, aprobada por ley en 1845, que procuraba una fiscalidad más justa basándose en datos sistemáticos de propiedades y cultivos (Segura, 1988; Muro et al., 1996; Pérez Picazo, 1998). A pesar de que durante años se ha sostenido que los amillaramientos son harto inexactos y que no se pueden considerar en esencia un catastro, las últimas investigaciones, al menos para la provincia de Barcelona, apuntan más bien a una precisión estadística máxima derivada de una minuciosa cartografía catastral (Nadal et al., 2005; Nadal, 2007). Sin embargo, no todos los municipios cuentan con planimetría y la existencia de la misma no implica necesariamente que el cuaderno (documento escrito en el que se hace el repartimiento impositivo y que hemos utilizado como fuente en este trabajo) participe de la misma exactitud, pues se detectan disfunciones entre mapas y tablas (Sans y Haro, 2000). Creemos que de cara al futuro la digitalización y trabajo mediante SIG de la cartografía de los amillaramientos ofrece grandes posibilidades para la geografía histórica, y de hecho ya se han practicado ejercicios parciales, entre otros: Font Casaseca (2008) para Sant Martí de Provençals; Tello y Garrabou (2007) para tres municipios del Vallès; o Giménez (2004) para El Masnou. Pero no ha sido este, cabe reiterarlo, nuestro método.

Los amillaramientos de 1850 en adelante constituyen la primera serie completa de información sobre usos agrarios del suelo de la que disponemos. Se encuentran todos en el Arxiu de la Corona d'Aragó y los consultamos individualmente, buscando siempre el primero disponible para cada municipio, entre 1850 y 1865 ; la mayor parte son de $1850 \mathrm{o}$ de pocos años después, de ahí que denominemos la fuente AM1850. El total de documentos vaciados es de 191, aunque se consultaron otros tantos en los que no había resumen municipal, que es la información específica que se tabuló. En ellos encontramos siete sistemas de unidades de superficie, que intentamos gestionar y convertir a unidades métricas a través de Llensá (1951), pero la precisión no se puede considerar absoluta, lo que crea un primer problema de exactitud en nuestros resultados.

Otro problema de precisión en la contabilidad de AM1850 surge de la agrupación en usos, que por nuestra parte adaptamos a nuestro sistema de clasificación en seis tipos, pero que en algún caso es problemática. De hecho, ahora sabemos gracias a los comentarios del profesor Enric Tello que es parcialmente errónea. Por otro lado, el propio profesor Tello nos comunicó en 2007 el hallazgo de una estadística sistemática tabulada, elaborada por el geómetra Pedro Moreno Ramírez, para el año 1858, en la que se listan todos los usos para el conjunto de los municipios de la provincia de Barcelona, sin necesidad de recurrir a todos y cada uno de los amillaramientos individuales. En este trabajo empleamos la base generada por nosotros en 2004-05, pero sin duda la futura explotación de la tabla de Pedro Moreno arrojará mayor exactitud.

Lamentablemente, nuestra procura de amillaramientos que recubrieran el total de los municipios de la región de estudio unas décadas después del corte temporal de AM1850 fue infructuosa; hacia 1920-30 algunos municipios realizaron un segundo amillaramiento, pero no todos, y hacia la década 1940 hay una nueva generación —ésta sí sistemática (Llovet, 1948). Pero la siguiente base de datos con la que contamos (CT1955) es demasiado 
próxima a la década de 1940 como para trabajar con datos de tan solo una década antes. De este modo, dista un siglo entre AM1850 y CT1955. Con ello perdemos la posibilidad de contar con una valiosa cuantificación del período anterior a la Guerra Civil, que probablemente, y como veremos en su momento, constituye el zénit de la agricultura periurbana barcelonesa como tal.

En relación con CT1955, cabe decir que se considera el primer catastro completo disponible para la totalidad de Catalunya (Majoral, 1979) y, por lo tanto, también de la región de estudio. Las fechas exactas del mismo son 1955 y 1956. En su día, nos fue imposible obtenerlo de forma directa en el Catastro. Afortunadamente, Roser Majoral lo había tabulado a mano con motivo de su tesis doctoral, aunque no lo llegó a utilizar por considerarlo una fuente desfasada para su investigación y con clases de usos excesivamente agregadas (Majoral, 1979) ${ }^{10} \mathrm{Su}$ tabulación es providencial para nuestra investigación. A pesar de los errores de cuantificación que detectamos y sobre la que ha redundado ya la bibliografía precedente, el catastro ha sido profusamente utilizado en geografía agraria en España (López Ontiveros, 1971).

En lo referente a las hojas 1T, empiezan a cumplimentarse en 1972 por el Ministerio de Agricultura para conocer los cultivos por municipios. De acuerdo con Majoral (1979), en la década de 1970 eran más fiables que los censos agrarios coetáneos y que el catastro. Las hojas municipales 1T correspondientes a 1973 fueron tabuladas mediante ordenador por Majoral (1979) y son las que utilizamos aquí. De todos modos, si en cierto modo es justificable que hacia la década de 1970 se detecten errores en las hojas 1T anuales, es incomprensible y altamente sorprendente que más de treinta años después la administración catalana (a la que se le transfirió en su día la prerrogativa de confeccionarlas) declare literalmente su «imposibilidad [...] de conocer con precisión la realidad de cada municipio», lo que conlleva «un grado de fiabilidad muy bajo» de las hojas 1T (DARP, 2000: 115; la traducción es nuestra). Al final de este artículo utilizamos 1T2004 puntualmente, pero su calidad es en efecto escasa. Tal vez por ello la administración ha dejado de cumplimentarlas.

Finalmente, el censo agrario es una fuente de datos que, si bien en las primeras ediciones se puede considerar problemática (Majoral, 1979), mejora en calidad gracias a la adecuación del censo español a los patrones censales europeos, ya en 1982, pero especialmente a partir de 1989 (Majoral, 1997). En este estudio se ha utilizado sobre todo CA1999 y algún dato de CA1982, CA1989 y, en primicia, del avance de CA2009, disponible en Internet desde julio de 2011. Como es sabido, el principal problema de trabajo con los censos agrarios es el hecho de que su base son las explotaciones, y no los municipios, lo que crea atribuciones superficiales erróneas. Aún así, los censos agrarios son hoy en día la estadística agraria más fiable de la que disponemos.

\section{Los usos agrarios del suelo a principios del siglo XVIII}

Tal y como se acaba de advertir, CT1717 no ofrece un recubrimiento completo; con todo, se ha ensayado su cartografía en la figura 2. En ella se puede deducir un contraste entre la franja litoral, con predominio de viñedos, y el interior, de cultivos cerealistas. La única excepción espacialmente coherente son los municipios del Pla de Barcelona de los que tenemos datos cuantitativos (Barcelona y L'Hospitalet), con predominio de cereales. A su vez, dos municipios separados del interior, Collbató y Terrassa, presentan un dominio de olivares. Veamos a qué responden estos usos.

10 Aprovechamos para señalar que Roser Majoral elaboró, sin que conste su autoría, una cartografía y un comentario de CT1955 para la provincia de Barcelona, publicado en Canet y Segura (1988: 56-57). 


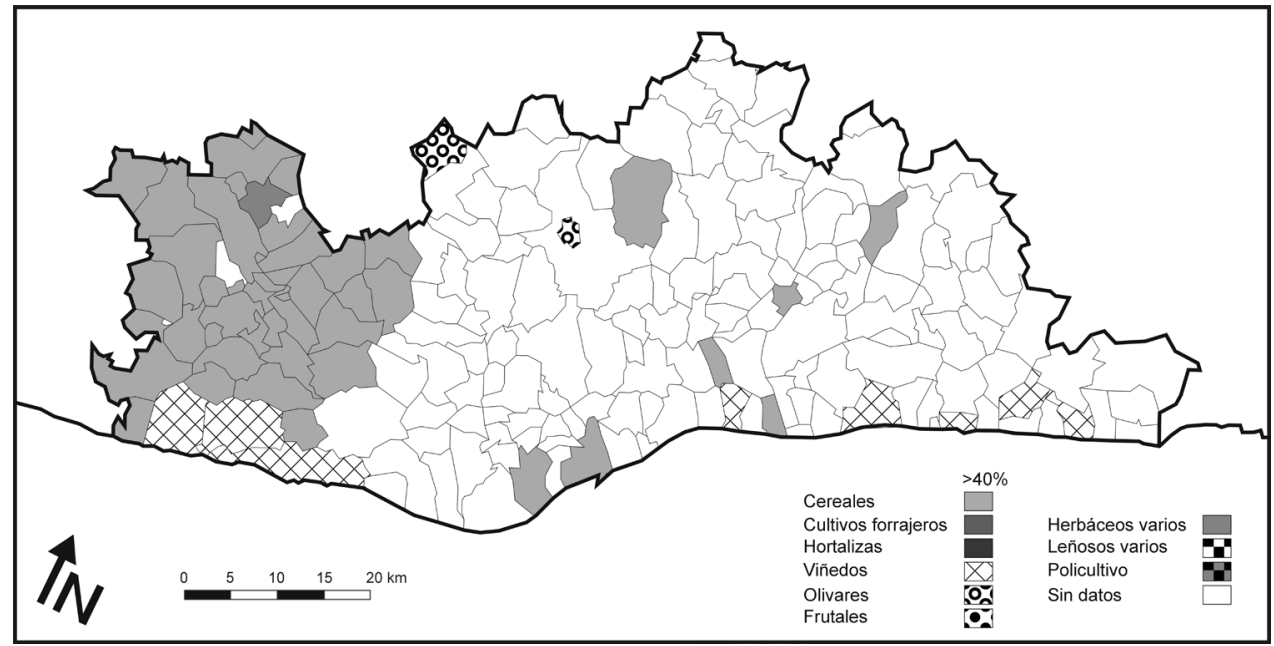

Figura 2. Preponderancia de usos agrarios del suelo $c a$. 1717.

Elaboración propia. Fuente: CT1717.

De entrada, cabe reseñar que los cultivos predominantes son los tres de la trilogía mediterránea. Esta tríada es una constante en la Catalunya moderna (Gual, 2008), pero en realidad proviene, a través del mundo medieval, de la herencia romana (Prevosti, 2005), y asimismo constituye la base dietética de la población en la ribera mediterránea durante milenios (Mazurek y Blanchemanche, 1992); obviamente, la trilogía es objeto privilegiado de carga impositiva y de vigilancia fiscal desde la época romana, de ahí su valor catastral. La especialización del litoral en viñedos está documentada ya desde la Baja Edad Media y tiene que ver con las posibilidades comerciales que ofrecen los puertos, mediante los que se pueden exportar tanto vino como aguardiente, aunque con grandes fluctuaciones según las cambiantes coyunturas históricas (Giralt, 1950, 2008; Vilar, 1962). Hasta que la destilación y la consiguiente producción de aguardiente no se generalicen a lo largo del siglo XVIII (Giralt, 1952; Vilar, 1962; Valls, 2003), el interior no puede plantar viñedos comerciales orientados a la exportación. De este modo, a inicios del setecientos la cordillera litoral impide aún al Vallès y al Penedès participar de las posibilidades con las que sí que cuentan ya el Maresme o el Garraf. Así, no es de extrañar que la primera geografía de Catalunya, más de un siglo antes que CT1717, mencione las siguientes como localidades vinícolas por antonomasia del país: «[e]n Mataró [Maresme] se hacen excelentes vinos claretes; en Sitges y Vilanova [Garraf] excelente malvasía» (Gil, 1599 [Ed. 2003]: 242; la traducción es nuestra).

En lo que se refiere al interior - básicamente, depresión Vallès-Penedès y cordillera prelitoral-, el dominio del cereal es evidente y se corresponde tanto con el secano (prácticamente absoluto en el Penedès, mayoritario en el Vallès) como con el regadío (relevante en el Vallès). La lectura de este uso como producto de una economía autárquica de base local o comarcal no tiene sentido en base a la investigación actual sobre el territorio catalán en la Edad Moderna (García Espuche, 1998), ya que, con la excepción mencionada de los vinos, sabemos que los productos del Vallès se trasladaban a la ciudad de Barcelona (Tello y Garrabou, 2007) y que los granos del Vallès y del Penedès debían circular como los del conjunto de Catalunya (Vilar, 1962; Dantí, 2008). En una frase axiomática, se ha escrito 
atinadamente que «[1] as comunidades rurales nunca actuaron a su aire, ni los transportes a grandes distancias nacieron ayer» (Tello, 1999: 201). En definitiva, los cereales dominan en la depresión prelitoral porque el pan es la base alimenticia de la sociedad de la época - de hecho, era así desde la Baja Edad Media y lo será hasta bien entrada la contemporánea (Cussó y Garrabou, 2006; Dantí, 2008) - y se adaptan bien al clima y al relieve llano de la zona. Sin embargo, existen en los municipios del Vallès-Penedès otros usos secundarios estadísticamente, sobre todo viñedos, olivares, huertas y regadíos para lino y cáñamo.

Cabe subrayar el hecho de que se localizan en la figura 2 dos municipios con predominio de olivares. Los olivos en el siglo XVIII están plantados de forma dispersa por todo el territorio y actúan frecuentemente como margen de campos; las olivas se destinan a la elaboración de aceite, pero también para usos artesanales. Sin embargo, existía entonces (Collbató en la figura 2) y de hecho todavía existe una concentración de olivares en un determinado sector, el piedemonte de Montserrat o Pla de Montserrat, alrededor de las villas de Olesa y Esparraguera, en las que constan almazaras desde la Edad Media (Vendranes y Rullier, 1996). Probablemente su enraizada presencia provenga del abastecimiento privilegiado del monasterio de Montserrat, pero en todo caso en el siglo xVIII su aceite se considera ya de calidad superior (Vilar, 1962).

Finalmente, resta referirse al entorno inmediato a Barcelona y a su eventual carácter de agricultura periurbana avant la lettre a principios del setecientos. En la figura 2 sólo dos municipios de la zona están representados, Barcelona y L'Hospitalet, y ambos se cartografían con un predominio de cereales. Pero sabemos que la realidad de entonces de ese ámbito es más compleja. Desde la Edad Media se había configurado el territori de Barcelona $\mathrm{y}$, dentro de éste, el hort $i$ vinyet (huerto y viñedo), sometidos mediante privilegio real a jurisdicción municipal directa de Barcelona, sobre todo el segundo ámbito y, en menor medida, el primero, donde coexistían dominios señoriales (Bassegoda, 1971). Mientras que el territori se extendía desde la cordillera litoral hasta el mar, desde Castelldefels al sur hasta Montgat al norte, en total unos $350 \mathrm{~km}^{2}$, el hort $i$ vinyet se circunscribía a un ámbito menor, de unos 50 o $60 \mathrm{~km}^{2}$, inferior al actual municipio de Barcelona $\left(101 \mathrm{~km}^{2}\right)$. Precisamente Felipe v, el inductor del CT1717, acaba con esta organización territorial al abolir el Consell de Cent barcelonés.

Sea como fuere, hay constancia desde el Medioevo y a lo largo de la Edad Moderna de la presencia de cultivos perecederos en el hort $i$ vinyet gracias al riego del Rec Comtal, canal derivado del río Besòs. Esta infraestructura presenta unos oscuros orígenes pero se sabe que fue construido, o tal vez restaurado, durante el condado de Miró i (947-966) (Capel, 1999; Martín, 1999). También se producen en el hort $i$ vinyet cereales y viñedos cuya orientación es fundamentalmente urbana y que por lo general se sitúan por encima del Rec. Por debajo de él, los campos son regados y destinados a hortalizas, usos agrarios de orientación protoindustrial (lino, cáñamo, etc.), cereales o prados para ganado que se consume en la ciudad (Busqueta, 1991; Fernàndez, 1993). Los cultivos del hort $i$ vinyet están protegidos por el Consell de Cent, que impide la entrada de ganado en los campos durante buena parte de las Edades Media y Moderna.

Esta política barcelonesa en el hort $i$ vinyet tiene como consecuencia histórica que el resto del territori se destine más bien a pastos. Ello da lugar a una conflictividad prolongada entre ganaderos y agricultores que parcialmente se encauza con la compra por parte de ciudadanos barceloneses de propiedades en el territori para poderlas destinar a pastos orientados a carnicerías, sobre todo en el Delta del Llobregat (Codina, 1971; Fernàndez, 1985). La evolución de la agricultura en el territori es harto compleja por la particular incidencia de Barcelona y de los propietarios ciudadanos. No obstante, están documentados desde la Alta Edad Media y a lo largo de la Baja Edad Media y de 
la Edad Moderna pequeños huertos en el territori cuya producción se deriva en parte al mercado urbano.

¿Pero por qué Barcelona y L'Hospitalet en la figura 2 no evidencian estos complejos usos del suelo, clasificables en cierto modo como periurbanos avant la lettre, de los que tenemos constancia tanto en el conjunto del territori como en el hort $i$ vinyet? En realidad, el CT1717 registra un 5\% de las tierras cultivadas del municipio capitalino como hortalizas y un $1 \%$ del de L'Hospitalet, que - hay que insistir en ello - no se encontraba históricamente en el hort $i$ vinyet, sino en el territori, lo que en cierto modo limitaba la orientación hortícola. Son proporciones muy modestas, pero en el caso del primero es el máximo valor relativo de toda la base de CT1717 (para los más de sesenta municipios de los que tenemos datos), lo que no es despreciable. ${ }^{11}$ Tratándose de Barcelona, es probable que la ocultación a la que se refería Llobet (1955a) no sea elevada y que, por lo tanto, el dominio cerealista del llano que rodea a la Barcelona amurallada sea incontrovertible a inicios del Siglo de las Luces. Por otras evidencias cualitativas en las que no podemos redundar aquí, sabemos que a inicios del siglo XVIII hay numerosos huertos en activo al abrigo del Rec Comtal, pero será a lo largo del setecientos y sobre todo en el ochocientos cuando se consolide esta orientación y se pueda comprobar su traducción en términos de usos del suelo agrarios. En este sentido, a finales del XVIII, el viajero Francisco de Zamora escribe lo siguiente, que da cuenta del desarrollo que había alcanzado la agricultura en el ámbito del antiguo territori:

«No es fácil explicar la hermosísima vista que se descubre desde este punto [Collserola], pues viéndose todo el corregimiento de Barcelona, desde Montgat a Castell de Fels, y en esta llanura la ciudad de Barcelona y los muchos pueblos, casas de campo, prados llenos de lienzos, árboles, sembrados, viñedos, huertas, etc., y terminando su costa en el mar, hace un conjunto superior a toda explicación, más propio de una pintura poética que de una narración» (Zamora, 1785 [Ed. 1973]: 32).

\section{Los usos agrarios del suelo a mediados del siglo XIX}

En el casi siglo y medio que transcurre entre CT1717 (figura 2) y AM1850 (figura 3), los cambios en los usos agrarios del suelo son mayúsculos y generalizados. Si en el anterior apartado nos referíamos a la continuidad existente en múltiples sentidos entre inicios del setecientos y los siglos anteriores, a lo largo del siglo XVIII y las primeras décadas del siguiente se produce una aceleración de las transformaciones. Un primer nivel de lectura de la figura 3 nos permite subrayar el carácter predominante que adquieren los viñedos en la región de estudio a mediados del ochocientos, cuya distribución y progresión analizaremos en lo sucesivo. En términos generales este avance - y, en paralelo, regresión de los cereales - se debe a cambios que expondremos a continuación, pero no ha de perderse de vista que los cereales, sustento de la dieta mediante la panificación, llegaban del exterior en años de carestía y en el siglo XIX obviamente se pasarán a importar de forma masiva (Cussó y Garrabou, 2006).

Asimismo, en la figura 3 comprobamos cómo se mantiene el núcleo oleícola de Olesa de Montserrat, a pesar de que superficialmente los viñedos ganan extensión, con casi total

11 A excepción de Sant Quintí de Mediona (Alt Penedès), con un 20\% de regadíos, sin duda relacionados con la potencia del manantial de Les Deus - nacimiento real del riu de Mediona, cuyo recorrido hasta la fuente suele ir seco - y posiblemente no solo destinados a hortalizas, sino al cáñamo (a finales del siglo XVIII se señala Sant Quintí como el único lugar del partido de Vilafranca que produce cáñamo; véase Barba, 1789 [Ed. 1991]). No obstante, el porcentaje del 20\% de Sant Quintí se corresponde con 42 ha, mientras que el 5\% de Barcelona equivale a 75 ha de huerta; son cifras que, como se ha dicho, hay que tomar con enorme cautela, pero que permiten aproximar las magnitudes. 
seguridad intercalados con olivos. De este modo, los olivares no aparecen como primer uso en Esparreguera (son el segundo uso, no obstante, con un recubrimiento del $43 \%$ ), lo que produce que entre Collbató y Olesa, los municipios que sí aparecen con predominio de olivos, se observe en la figura 3 un cuño vitícola. A su vez, los cereales mantienen su preponderancia en el Vallès más oriental, Montseny incluido, así como en algunos municipios montañosos del Alt Maresme y en el Moianès. Este patrón cerealista será explicado más adelante. Finalmente, en Barcelona y su entorno inmediato se entrevén usos distintos, aparentemente cerealistas, pero en realidad enmascarando una importancia creciente de las hortalizas; de hecho, aparecen ya tres municipios con predominio de hortalizas, tal y como explicaremos al final de este apartado. En efecto, se está forjando a mediados del siglo XIX en ese núcleo central una verdadera agricultura periurbana para un mercado urbano expansivo.

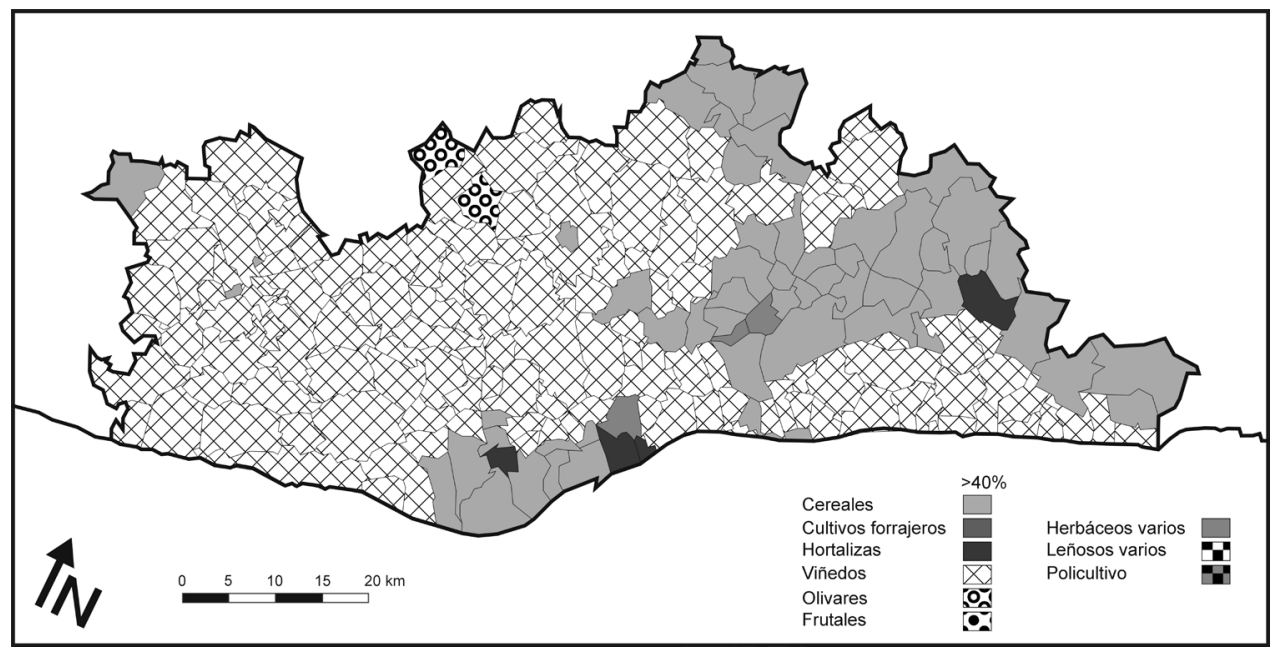

Figura 3. Preponderancia de usos agrarios del suelo $c a .1850$.

Elaboración propia. Fuente: AM1850.

Empecemos el recorrido por el principal resultado derivado de la figura 3: la expansión del viñedo. Si en la figura 2 su distribución se circunscribe al litoral, en la figura 3 la generalización espacial es evidente, habiendo traspasado la cordillera litoral e implantándose en buena parte de las llanuras prelitorales e incluso en la cordillera prelitoral. Esta progresión es característica del siglo XVIII y ha sido profusamente estudiada, entre otros, por Giralt (1950, 1952, 2008), Llobet (1955a, 1955b, 1968), Vilar (1962), Valls (2003) o Planas (2007). La dinámica expansiva del viñedo se debe en primera instancia a la generalización del aguardiente, que, como se ha dicho más arriba, permite participar al interior del comercio de productos vitivinícolas que en los siglos anteriores solo había sido posible para el litoral. Giralt $(1952,2008)$ ha fijado 1692 como fecha de la primera destilería instalada en Vilafranca del Penedès, es decir, en el interior de la región. Esta es la semilla del cambio de una comarca, el Alt Penedès, que hasta ese momento había sido cerealista y que a partir de entonces modifica su faz paisajística de forma contundente. Durante el siglo XVIII la región de estudio orienta en términos generales sus aguardientes al mercado del Norte de Europa y a las colonias americanas (sobre todo con la real cédula 


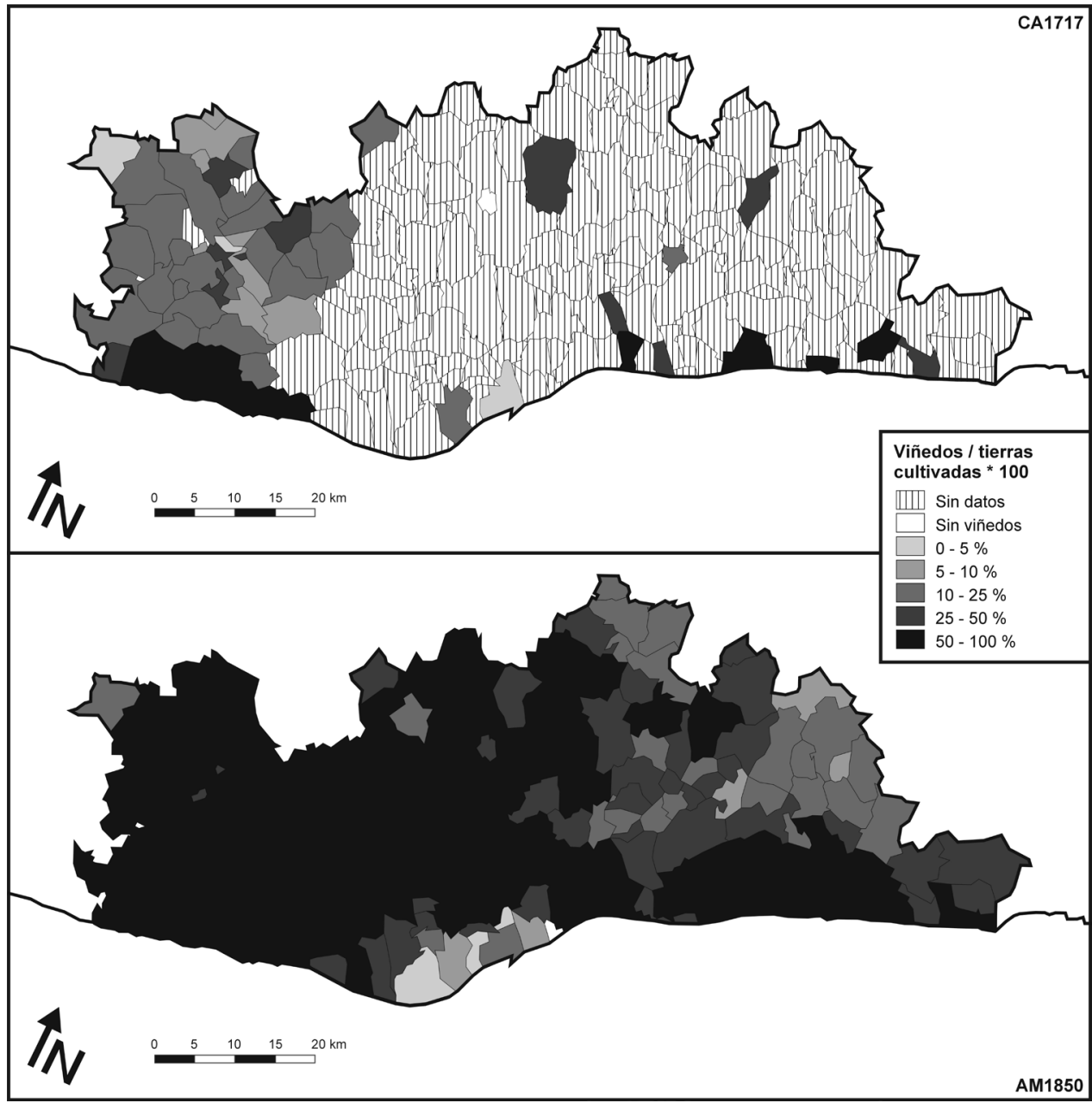

FIGURA 4. Porcentaje de la superficie vitícola respecto al total de tierras cultivadas $c a .1717$ y ca. 1850.

Elaboración propia. Fuentes: CT1717 y AM1850.

de Carlos III de 1778 de libertad comercial con América). En el siglo XIX la preferencia por la producción de aguardientes cede ante la de vinos, cuyo transporte únicamente es posible gracias a la implantación del ferrocarril (Valls, 2003). Los vinos se derivan entonces de forma mayoritaria hacia el mercado interior y al resto de Europa, en especial a medida que la filoxera ataca a los viñedos franceses, en las décadas de 1860 y 1870, lo que desata un repunte de las viñas catalanas hasta que no llega la filoxera a éstas, unos años después.

El patrón de los viñedos del ochocientos lo podemos detallar gracias a la figura 4 . Este mismo mapa también nos permite comprobar cómo en los municipios interiores, en los que en ningún caso a principios del setecientos se sobrepasa el umbral del $50 \%$ de viñedos en los usos agrícolas del suelo, éste se suele superar con creces unos 130 años después. La expansión para CT1717-AM1850 y el predominio en AM1850 de los viñedos en el Alt Penedès, el interior del Baix Llobregat y el Vallès Occidental son generalizados. En AM1850 
únicamente hay poca viña, o ninguna (el único municipio de los casi doscientos del área de estudio que consta sin viñedo es Sant Adrià de Besòs), alrededor de Barcelona y en el Vallès más oriental. La crisis de la plaga del oídio a mediados del siglo XIX es severa y afecta duramente a los viñedos (Llobet, 1955b; Giralt, 1990; Nadal y Urteaga, 2008), pero la expansión se reinicia después, en especial a partir de 1860, cuando se desata la fiebre vitícola mientras Francia es atacada por la filoxera. AM1850 tal vez no refleje el impacto del oídio, que produce una contracción del viñedo a lo largo de la década 1850-1860, a la que le sucede una nueva expansión.

Con todas las cautelas expresadas en el apartado metodológico, nuestro sumatorio de viñedos en AM1850 es de 72.380 ha para el total regional y Giralt (1990: 235) ofrece para 1889 y todos los partidos judiciales de la región de estudio una cifra de 84.431 ha, lo que supone un incremento del $17 \%$. Probablemente esta última cifra está cerca del máximo superficial del viñedo previo a la llegada de la filoxera, que en 1883 aparece en el Alt Maresme y alcanza al Alt Penedès en 1886 (Iglésies, 1968). Pero es evidente que este desarrollo vitícola del siglo XVIII - y, sobre todo, del XIX - no tiene que ver con su localización próxima a Barcelona, en el ochocientos en proceso de expansión urbana e industrial. Más bien responde a una temprana inserción en los circuitos de comercio internacional de las producciones vitivinícolas catalanas, próximas o no a la capital, con diferentes ciclos variables a lo largo de los dos siglos.

Los siglos XVIII y XIX no constituyen únicamente las centurias de la expansión vitivinícola, sino que también están dominados por el crecimiento de la ciudad de Barcelona. Desde la Edad Media la capital presenta con matices una población estable (García Espuche, 1998), y a partir de inicios del setecientos comienza una senda imparable de aumento demográfico. Así, en 1718 contabiliza unos 35.000 habitantes, una población similar a la alcanzada en el siglo XIV, pero a finales del siglo XVIII supera los $110.000 \mathrm{y}$, un siglo después, el medio millón - aunque tal cifra debe ser parcialmente atribuida a la anexión de los municipios cercanos a la ciudad amurallada. Este crecimiento no implica aún la desaparición de usos agrarios del suelo, por lo menos no antes de finales del ochocientos. En cambio, significa la conformación progresiva de un cinturón de avituallamiento hortofrutícola para el consumo urbano, que, a partir de los antecedentes históricos mencionados, se va vigorizando en el siglo XVIII, se desarrolla en el XIX y se consolida a principios del xx. En paralelo, no se debe perder de vista que, como bien han explicado Cussó y Garrabou (2006), este consumo urbano va alejándose de la dieta centrada en el pan e incorpora progresivamente en la cesta productos que tienen reflejo en los usos del suelo que observamos aquí - hortalizas, lácteos, etc. - y aún otros que no podemos detectar con las fuentes disponibles pero que sin duda se añaden a la alimentación de la ciudad, en especial la carne.

En la figura 3 se observan ya tres municipios con predominio estadístico de la especialización hortícola ligada al mercado urbano: Sant Martí y Sant Adrià en el Pla de Barcelona y Cornellà en el Delta. La figura 5, que representa solo las proporciones de los regadíos totales (regadíos genéricos, hortalizas, frutales de clima templado y naranjales), evita la ocultación ejercida por el uso predominante en la figura 3. Así, vemos cómo en la figura 5 a los dos primeros municipios se les suma Sant Andreu; y al segundo, una serie de términos municipales dispuestos en forma de corredor, en la ribera izquierda del río Llobregat (Molins, Sant Feliu, Sant Joan, Sants, etc.). Ambas áreas responden a sendos canales. En el primer caso, el Rec Comtal, cuya mejora se produce en el reinado de Carlos III - en el edificio de la mina que aún se conserva en Montcada consta que las obras de modernización finalizan en 1778. En el segundo, el Canal de la Infanta, que recoge las aguas del río Llobregat por su margen izquierdo y es inaugurado en 1819. En el caso del Rec, se documenta el proceso de intensificación agraria ligado al regadío, con rotaciones 
complejas entre hortalizas, forrajes, legumbres y prados de indianas destinados a la protoindustria (Giralt, 1990; Martín, 1999). A su alta productividad de entonces ayudan los estiércoles de la ciudad de Barcelona, tal y como atestiguan sus contemporáneos en varias fuentes que han llegado hasta nosotros.

En lo referente al Canal de la Infanta, se ha debatido si estaba destinado a fines industriales o agrarios; las últimas investigaciones sustentan la idea de que más bien a los segundos (Tribó, 2005). El hecho de que Cornellà aparezca con uso hortícola predominante (figura 3) es denotativo de la nueva situación propiciada por el canal, tan solo unas tres décadas después de su inauguración. Pero no es el único municipio que experimenta un cambio de usos del suelo, ya que esta transformación afecta a todo el margen izquierdo del río, de Molins hasta L'Hospitalet y Sants (figura 5). Los usos hortícolas se expanden, pero también los frutales, que llegarán a ser dominantes en la Vall Baixa (figura 6), y otros usos secundarios como el arroz (para atenuar el ascenso de las sales), el cáñamo, el maíz, etc. La apertura de la línea de tren entre Molins y Barcelona en 1853 (Font Garolera, 1999) refuerza la inserción en el mercado urbano de la baja ribera izquierda del Llobregat (Tribó, 1995, 2005).

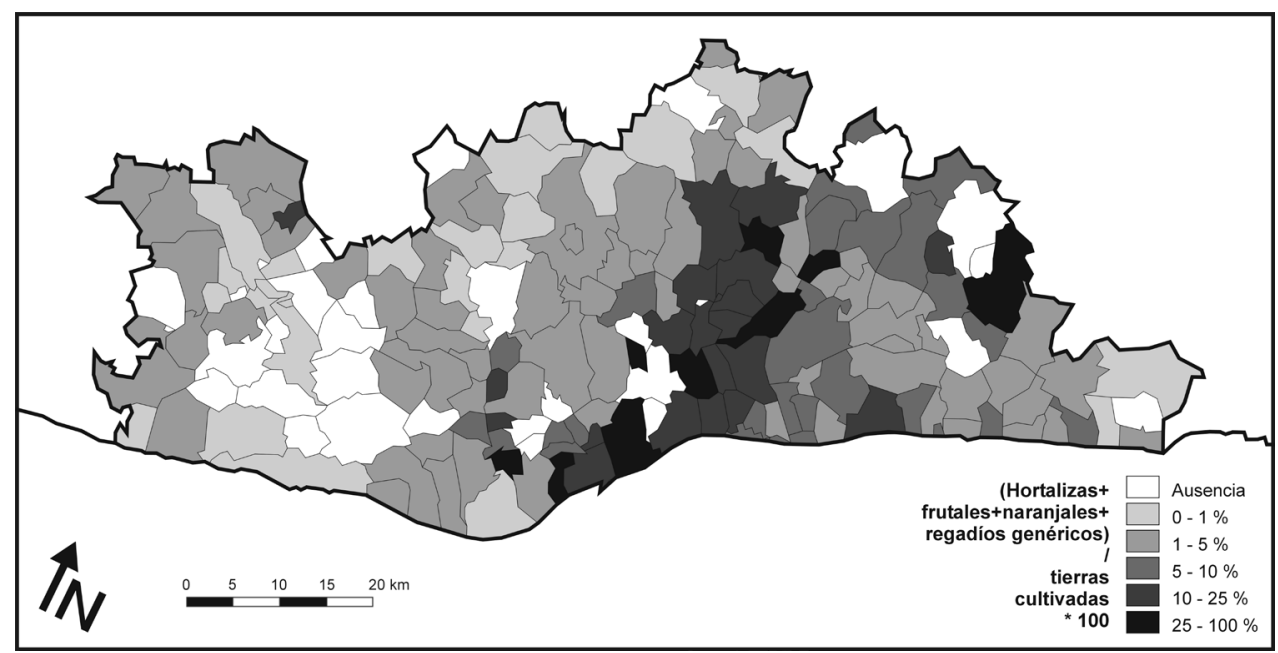

FIgURA 5. Porcentaje de los regadíos intensivos (suma de regadíos genéricos, hortalizas, frutales de clima templado y naranjales) respecto al total de tierras cultivadas $c a .1850$.

Elaboración propia. Fuente: AM1850.

A partir de 1850 (por lo tanto, no reflejado aún en las figuras 3 y 5), el margen derecho del Llobregat también construye su propio canal, que se inaugura de forma inicial en 1858 y definitiva en 1885. La existencia de dos canales paralelos resulta en una compleja negociación por los caudales (Giralt, 1990; Tribó, 1995, 2005). En el margen derecho también los usos del suelo irán transitando progresivamente hacia el dominio hortícola a lo largo de la segunda mitad del siglo xIx. El proceso, no obstante, es mucho más lento en la orilla derecha que en la izquierda. El dominio de los cereales que aparece en este sector en la figura 3 no encubre hortalizas o árboles frutales (figura 5) y suele consistir en rotaciones de trigo y legumbres (Codina, 1995). El territorio deltaico seguirá siendo pobre y cerealista, aunque a finales del XIX se instalan en la franja costera del Delta, en antiguos 
humedales y concretamente en el espacio que actualmente ocupa el aeropuerto del Prat, las dos primeras grandes granjas lecheras de la región de estudio (Ràfols, 2000). Pero sus pastos y forrajes no aparecen obviamente en AM1850, y en todo caso no llegarán a generar un cinturón lechero, pero su presencia puntual denota un cambio de ciclo en el Delta del que hablaremos en el próximo apartado.

Aunque invisibles en la figura 3, se aprecia en la figura 5 cómo algunos municipios costeros del Maresme contienen regadíos intensivos. En términos estrictamente superficiales no son de magnitudes destacables, a excepción de la capital comarcal (Mataró) y de algunos municipios del Baix Maresme, pero cualitativamente el Maresme registra a mediados del siglo XIX regadíos orientados al mercado urbano. Tal y como Llobet (1955a) analizó de forma magistral, se trata de una producción intensiva de hortalizas, legumbres, patatas y frutas (naranjas y fresas, principalmente) que se transporta a Barcelona y que se beneficia de las concesiones de minas otorgadas desde el siglo XVIII. Llobet (1955a) ofreció dos fechas de la segunda mitad del ochocientos que acotan esta primera agricultura intensiva en el Maresme: por un lado, en 1876 se inicia la exportación de patata tempranera a Francia, lo que incentivará a partir de entonces su cultivo y expandirá el alcance de la agricultura intensiva del Maresme, que de ser periurbana de Barcelona en el siglo XIX pasará a ser en pocas décadas una agricultura orientada a la exportación; por otro lado, en 1891 una helada arruina a todos los naranjales, cuya producción se estaba derivando al mercado barcelonés pero también a la exportación hacia Francia, que no se vuelven a replantar.

Queda por referir el dominio cerealista del extremo nororiental de la región de estudio (figura 3). La continuidad del cereal en esas áreas no se debe interpretar en un sentido inmovilista, sino que en general se mantiene porque es viable económicamente (Garrabou et al., 2007). Además, se producen innovaciones como la irrigación (correlaciónense los regadíos de la figura 5 con el predominio del cereal en la figura 3) o la introducción sistemática de los forrajes y de las legumbres en las rotaciones, con la consiguiente desaparición de los barbechos. Las legumbres adquieren de este modo un papel fundamental en la alimentación (Cussó y Garrabou, 2006). También en el setecientos y el ochocientos aparecen en el Vallès más oriental los prados regados que permiten incrementar la carga ganadera, destinada en lo fundamental a Barcelona, y se extiende el cultivo del cáñamo, exportado a Inglaterra (Vilar, 1962; Garrabou y Planas, 1998). Todo ello no impedirá que en el máximo prefiloxérico el viñedo aumente mucho en el Vallès, incluso más allá de los porcentajes de la figura 4, dados los réditos que de él se podían obtener, que posiblemente fueron substanciales para las explotaciones pequeñas de agricultores pobres (Garrabou et al., 2007; Tello y Garrabou, 2007).

En otro orden de cosas, cabe decir que en el Vallès cerealista de entonces se documenta la presencia de huertas con hortalizas y patatas que, como las legumbres, se consumen en Barcelona (Garrabou y Planas, 1998). Sabemos que los tubérculos vallesanos se derivan a la capital, mientras que los del Maresme se suelen exportar. En todo caso, en el Vallès más oriental no estamos ante un ámbito de características asimilables a los territorios que ya podemos denominar de agricultura periurbana a mediados del siglo XIX: determinados sectores del Maresme y los regadíos próximos a Barcelona - en concreto, las áreas regadas por el Rec Comtal y el Canal de la Infanta, y poco después también (aunque no recogido por AM1850) por el Canal de la Dreta del Llobregat.

\section{Los usos agrarios del suelo a mediados del siglo $\mathrm{XX}$}

Ya hemos adelantado en el apartado metodológico el problema que representa no contar con una fuente adecuada en el primer tercio del siglo xx, que nos hubiera permitido medir 
lo que probablemente constituye el «momento dorado» de la agricultura periurbana barcelonesa. Dado que aquí nos estamos refiriendo a los datos estadísticos, debemos dejar de lado las evidencias cualitativas y parciales con las que contamos para el período previo a la Guerra Civil y, por consiguiente, efectuar un salto hasta CT1955. No obstante, a partir de CT1955 aportaremos las consideraciones necesarias para entender la evolución desde AM1850, lo que nos obligará a referirnos al siglo que se interpone entre ambas fuentes.

La primera constatación que se extrae de la observación atenta de la figura 6 es la preponderancia que vuelven a tener los cereales unos dos siglos después de que fueran vapuleados por el viñedo. Ahora estos predominan por todo el Vallès - aunque en parte de esa comarca no habían dejado de ser el uso principal (figura 3) - , el Alt Penedès y algunos municipios del litoral, en especial en el Delta del Llobregat y el Alt Maresme. Con todo, este cambio de usos agrarios del suelo que refleja la figura 6 se circunscribe a la coyuntura inmediatamente posterior a la Guerra Civil, durante la década de 1940 y parte de la siguiente, aunque ya no en la de 1970 (figura 10). La autarquía post-bélica se manifiesta, entre otras cosas, en la obligación de la plantación de cereales, la planificación de la producción y del consumo (cartillas de racionamiento) y unos precios altos del pan (Llobet, 1955b; Pujol y Benelbas, 1989; Majoral, 2006). Todo ello da como resultado una extensión de los cereales en campos que anteriormente tenían otros usos, sobre todo viñedos, pero probablemente también hortalizas y demás. No obstante, los coetáneos viven este período como una anomalía y Llobet (1947 [Reed. 1990]: 242) escribe en su tesis doctoral sobre el Montseny, sagaz y premonitoriamente: «La normalización de los abastecimientos comportará un retorno a la situación de los cultivos antes de la guerra, que eran, en definitiva, el resultado de la situación geoeconómica del momento normal del mercado» (la traducción es nuestra).

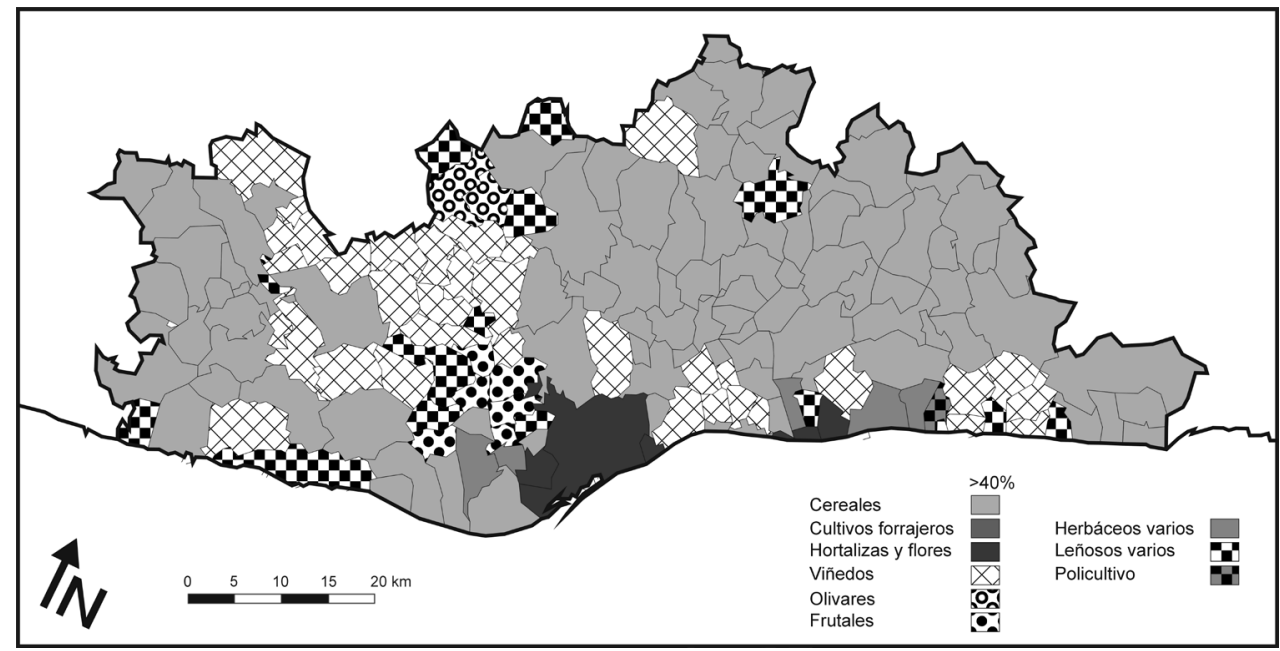

FIGURA 6. Preponderancia de usos agrarios del suelo en 1955-56.

Elaboración propia. Fuente: CT1955.

De todos modos, la figura 6 permite realizar algunas lecturas más que plantean interés. De entrada, se comprueba de nuevo cómo la especialización olivarera del piedemonte de Montserrat, ya apreciable más de dos siglos atrás (figura 2), se mantiene, aunque en el mu- 
nicipio de Collbató se cartografían leñosos diversos por la importancia que alcanza también entonces el viñedo allí. Más allá de este núcleo olivarero, la figura 6 expresa tres usos que tienen presencia destacable en ámbitos concretos: el viñedo, los frutales y las hortalizas y las flores. Nos dedicaremos a ellos en lo sucesivo de este apartado.

En cuanto a los viñedos, en el apartado anterior hemos detenido nuestras consideraciones en el máximo prefiloxérico. La propagación de la plaga de la filoxera y el alcance de sus efectos en la agricultura catalana es un tema profusamente estudiado (entre otros, Iglésies, 1968; Garrabou y Pujol, 1988; Giralt, 1990; Piqueras, 2005) sobre el que huelga redundar aquí. Contamos también con valiosas investigaciones que evalúan la misma cuestión a escala comarcal - por ejemplo, Planas (2007) para el Vallès, Llobet (1955a, 1955b) para el Maresme o varias de las contribuciones reunidas por Colomé (2003) para el Penedès. De toda esta bibliografía podemos extraer a nuestros efectos la idea de que la filoxera da paso a tres situaciones en términos de usos: la replantación con cepas inmunes a la misma, el cambio de cultivos o el abandono definitivo. No podemos cuantificar con precisión cada una de estas opciones. En general, las comarcas más orientales del ámbito de estudio, así como los lugares más montañosos, abandonan rápidamente el viñedo e incluso se pierde superficie agraria al no haber un uso agrario substitutivo. La figura 7 representa la evolución del total de las tierras cultivadas entre AM1850 y CT1955; obviamente, tal mapa exige muchas cautelas metodológicas pero parece atinado deducir de él que la mayor parte de los municipios que pierden mucha superficie agraria se encuentran en las áreas montañosas (Montseny, Sant Llorenç, Muntanyes d'Ordal, Montserrat, Garraf, etc.), lo que responde a una muerte no compensada de viñedos por filoxera y consecuente aforestación.

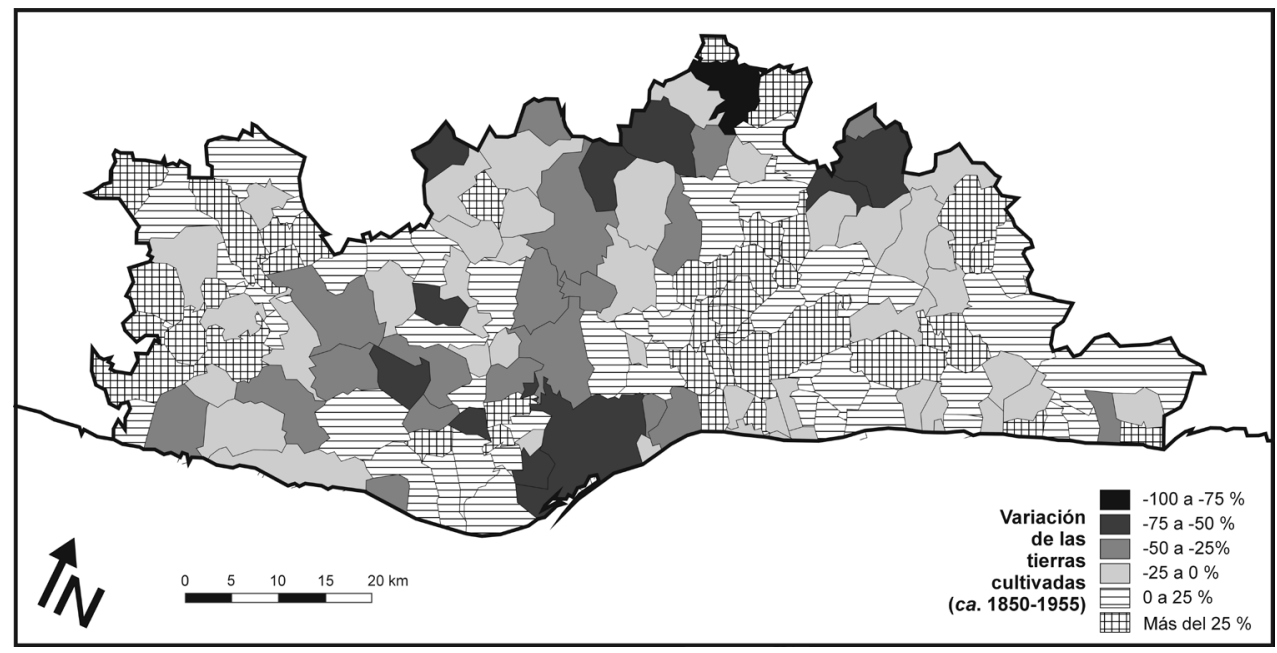

FIGURA 7. Evolución de las tierras cultivadas (ca. 1850 - 1955-56).

Elaboración propia. Fuentes: AM1850 y CT1955.

En lo que se refiere a la substitución de viñedos por cepas resistentes y, por consiguiente, la continuidad del uso del suelo, la figura 6 nos permite captar tres áreas disyuntas en las que, incluso en la autarquía post-bélica, el predominio vitícola se mantiene: parte del Baix Maresme, parte del Alt Maresme, y parte del Alt Penedès y — contiguo con éste- el interior del Baix Llobregat. A partir de las investigaciones mencionadas más arriba, sa- 
bemos que se replantaron viñedos en más zonas, pero medio siglo después, CT1955 sólo cartografía estos tres núcleos. Los municipios del Baix Maresme situados en la cordillera litoral se corresponden en lo fundamental con el área del vino de Alella; sin que podamos extendernos en su casuística, lo que sucede en este sector es que en los secanos del Baix Maresme se replantan los viñedos y se opta por una estrategia de individualización alrededor de la marca Alella, que al fin y al cabo acabará conduciendo a la primera denominación de origen de la región de estudio, creada en 1953 (Paül, 2011). ${ }^{12}$ En el caso del Alt Maresme, los municipios que aparecen con viñedo en CT1955 responden a la imposibilidad de cambiar el uso hacia los cereales, dadas las fuertes pendientes de la zona; no obstante, poco después de 1955 se arrancan muchos viñedos para extender el cultivo que simbolizará la transformación agraria en ese sector a partir de la década de 1960, el fresón (Rosés, 1989).

Finalmente, queda por referir el Penedès como caso de continuidad vitícola (véanse las figuras 3 y 6 ). Se trata de una persistencia que la figura 6 matiza, pues los viñedos aparecen relegados a la parte norte del Baix Llobregat y a la banda más oriental del Alt Penedès, pero tanto parte de la comarca del Garraf como la banda occidental del Alt Penedès constan como cerealistas. En realidad, este patrón manifiesta algo parecido a lo que hemos visto que sucede en el Alt Maresme: en las zonas más quebradas, el tránsito a los cereales es imposible y por lo tanto se mantienen los viñedos, aún con la coyuntura favorable a los cereales; ${ }^{13}$ en cambio, las zonas llanas experimentan un cambio de usos hacia los cereales durante la autarquía, pero en 1973 (figura 10) vuelven a ser de dominancia vitícola. Tal y como observó atinadamente Llobet (1959) y como Colomé (2003) documenta de forma extensa, el viñedo post-filoxérico en el Penedès ya no se orienta a la producción de vino, sino progresivamente a los espumosos, lo que a medio plazo se traduce en términos legales en la coexistencia de dos denominaciones de origen en una misma área. ${ }^{14}$ Así, de la crisis de la filoxera surge el germen de lo que será el cava, convertido actualmente en garante de la continuidad del viñedo en el Alt Penedès.

Más allá de la replantación de los viñedos, o de su arranque y no substitución por otro uso agrario, existe una tercera casuística: el cambio de usos agrarios. Giralt (1990) observa una substitución de antiguas viñas por olivares, pero en la comparativa AM1850-CT1955 no tenemos evidencias de ello en un primer nivel de lectura, lo que implica que debió ser puntual o de magnitudes modestas. Otros cultivos que también substituyen a los viñedos son los almendros, los algarrobos o los avellanos, pero no se aprecian en la cartografía de predominancias. Mediante CT1955 únicamente podemos detectar un área en la que se encuentra un cultivo alternativo substitutivo de la viña y tenemos constancia de una segunda que, aunque no visualizable en la figura 6, experimenta una transformación perceptible.

12 «Orden de 29 de abril de 1953 por la que se dispone la constitución del Consejo Regulador para la denominación de origen «Alella»», en $B O E \mathrm{n}^{\circ} 133$ (13/5/1953), pp. 2772-2773.

13 La zona más oriental del Alt Penedès y del interior del Baix Llobregat mantiene su identidad vitivinícola desde finales del siglo XVIII (figura 3) hasta después de CT1955 e incluso la década de 1970 (figura 10). Sin embargo, hoy en día ha perdido esta dominancia de usos (figura 11) y su carácter agrario (figura 15). En el pasado se percibió esta zona como autónoma respecto al Penedès, pues aparece en la lista de futuribles DO en el Estatuto del Vino republicano bajo la marca Martorell («Ley de 26 de mayo de 1933», en Gaceta de Madrid, $n^{\circ} 155$ (4/6/1933), pp. 1682-1683). Originalmente esta zona más oriental centrada en Martorell no se englobó en la primera DO Penedès (1958), lo que obligó al Ministerio a considerarla una zona aparte (Sanz, 1975), aunque en 1976 fue incluida en la DO Penedès ampliada.

14 DO Penedès, para el vino, y DO Cava, para el cava. Las primeras disposiciones para ambas son de 1958 y 1986, respectivamente. Véanse: «Orden de 28 de julio de 1958 por la que se autoriza la constitución del Consejo Regulador de la Denominación de Origen "Panadés"», en BOE n 222 (16/9/1958), p. 8182; y «Orden de 27 de febrero de 1986 por la que se establece la reserva de la denominación del "Cava" para los vinos espumosos de calidad elaborados por el método tradicional en la región que se determina», en $B O E, \mathrm{n}^{\circ} 51(28 / 2 / 1986)$, pp. $7750-7751$. 
La primera área se comprueba en la figura 6, en algunos municipios de las Muntanyes d'Ordal. En ellos muchas de las viñas afectadas por la filoxera se replantan de frutales de secano, fundamentalmente cerezos y melocotoneros (Paül y Serrano, 2005); esta conversión es trascendente, porque de la economía vitícola insertada en un comercio extrarregional (nacional e internacional) se pasa a una producción orientada al mercado barcelonés. La segunda área es un sector reducido, la huerta de Vilanova, cubriendo el municipio homónimo y Cubelles; en este segundo caso, el cambio consiste en la implantación ex novo de un regadío mediante la construcción del pantano de Foix, inaugurado en 1912 (Pomés y Barriendos, 2002); el propósito declarado de esta infraestructura es la creación de una zona de hortalizas que emule las otras comarcas costeras especializadas en tal producción. La presa sufre constantes problemas técnicos y, por consiguiente, el cambio de usos es lento y limitado, pero refleja, como en el caso de Ordal, la voluntad de reorientar la agricultura hacia el mercado urbano.

Al principio de este apartado hemos indicado que, más allá de los cereales y del viñedo, la figura 6 permite detectar un área de frutales y otra de hortalizas y flores. Nos referiremos a ellos en este orden. La de frutales de clima templado se localiza en el sector conocido como la Vall Baixa y se beneficia de los dos canales laterales derivados del Llobregat, mencionados en el apartado anterior (Infanta y Dreta). Si bien mediante AM1850 (figura 3) este sector no se intuía aún, en CT1955 (figura 6) es visible. Como ya se ha dicho, la orientación predominante de melocotones, ciruelas, etc. es Barcelona, pero a partir de la década de 1910 también se inicia su exportación a Francia (Tribó, 2005). La Guerra Civil y la Segunda Guerra Mundial truncan esta trayectoria. En la figura 8 representamos los resultados de CT1955 para los frutales de clima templado y en ella se observa una concentración en el Baix Llobregat, tanto en el secano en antiguos viñedos (Muntanyes d'Ordal), como en el regadío del Llobregat (Vall Baixa).

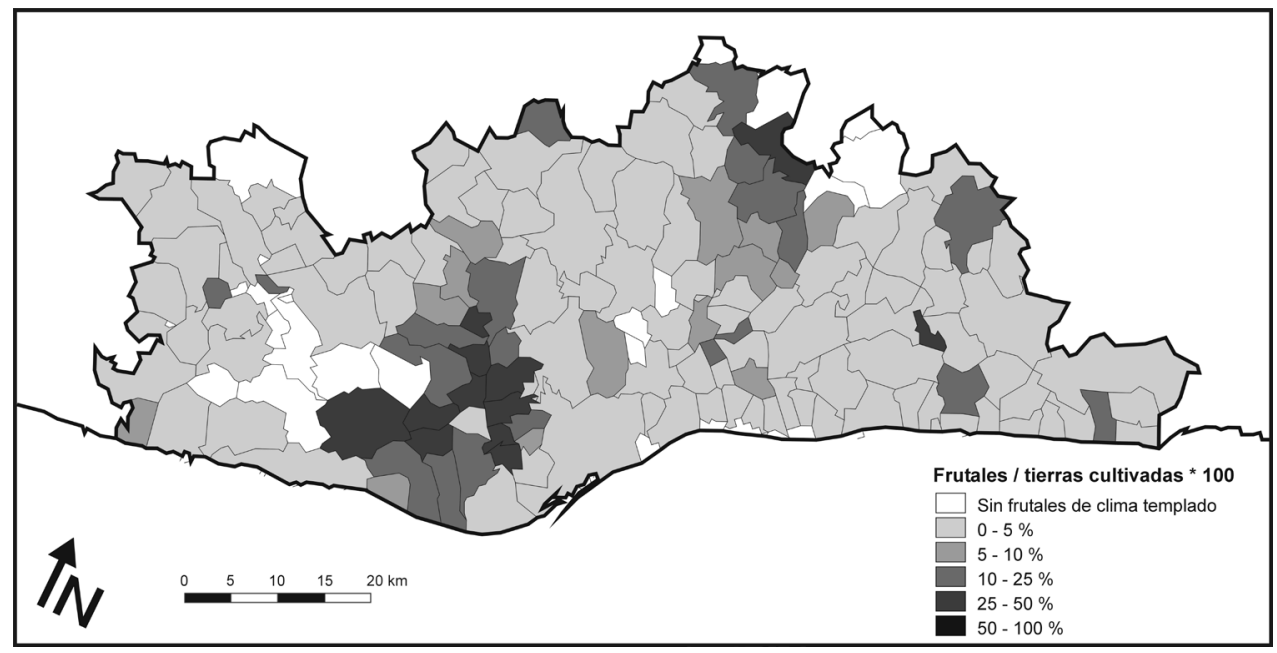

Figura 8. Superficie de frutales de clima templado en 1955-56.

Elaboración propia. Fuente: CT1955. 
La figura 6 enmascara la importancia de la extensión de las hortalizas en la región de estudio en 1955-56. Más allá de la primacía circunstancial de los cereales, en varios municipios sucede que estadísticamente las hortalizas son el segundo uso, a veces a escasa distancia de los cereales, lo que impide la detección de su importancia. Sin embargo, en la figura 6 se intuye ya una preponderancia de las hortalizas en Barcelona y alrededores y en los municipios costeros del Baix Maresme. Recordemos que mediante AM1850 (figura 3) era difícil aún ver el alcance del predominio de las hortalizas, pero mediante CT1955 (figura 6) es más palpable. Y aún más, si representamos únicamente las hortalizas y las flores (figura 9), el patrón territorial aparece más nítido: esta producción se extiende en 1955-56 desde el Delta del Llobregat hasta el Alt Maresme, a lo largo del litoral. Podemos apreciar en esta orla costera cambios respecto a la situación descrita en el anterior apartado, lo que merece un detalle particular.

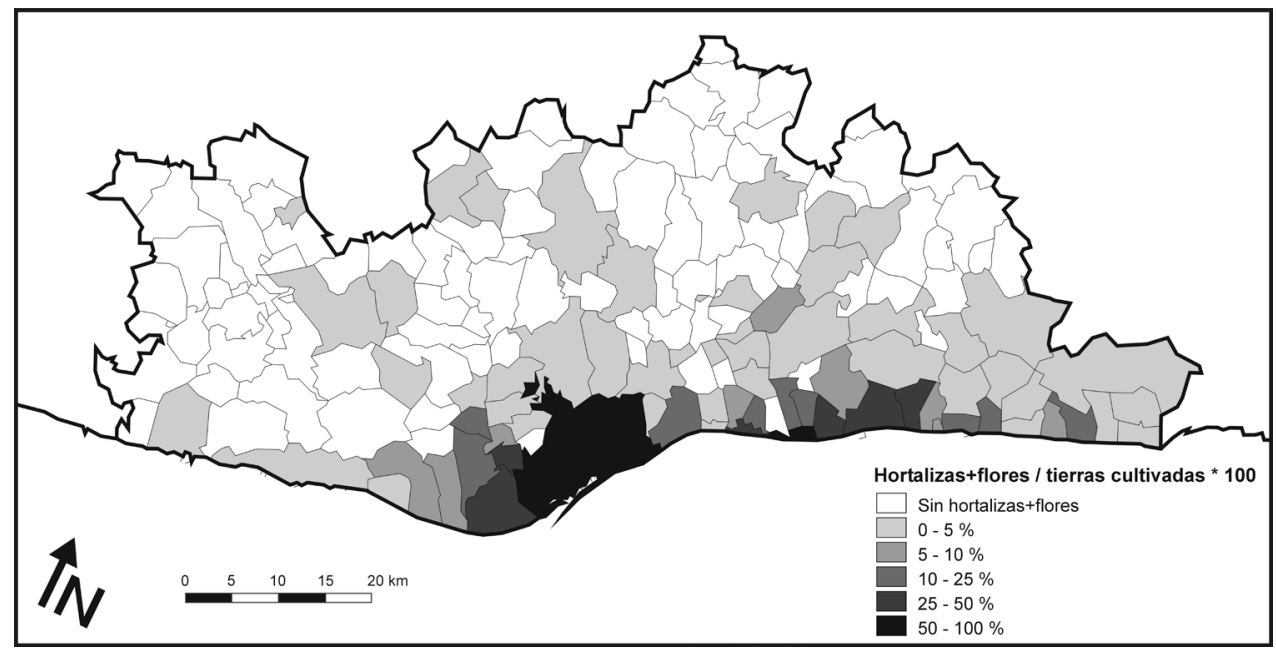

FIGURA 9. Superficie de hortalizas y flores en 1955-56.

Elaboración propia. Fuente: CT1955.

En primer lugar, el Delta del Llobregat que habíamos caracterizado para el ochocientos era fundamentalmente cerealista. Pero la llegada de los dos canales laterales y, sobre todo, el descubrimiento del agua artesiana a finales del siglo XIX, concretamente en una de las primeras vaquerías mencionadas, transforman la agricultura deltaica de forma absoluta. En pocos años cambia el uso del suelo del cereal a las hortalizas - en especial, alcachofa y lechuga trocader en el delta más oriental y melones y espárragos en el más occidental - para el abastecimiento de Barcelona, primero, y para la exportación, poco después, aprovechando los canales de comercialización abiertos por la fruta de la Vall Baixa (Tribó, 2005). Asimismo, perviven y se expanden las vaquerías, con forrajes para alimentar al ganado vacuno en el propio Delta y en la ciudad - a Deffontaines (1949) le impresionan las ocho siegas anuales de alfalfa-; de todos modos, las granjas lecheras no logran aguantar a medio plazo la competencia con las hortalizas. El esplendor de este modelo de producción hortícola se alcanza entre 1920 y 1936, en la denominada «época dorada» de la agricultura deltaica, que a su vez culmina el proceso histórico acumulado de desecación de las antiguas lagunas (Codina, 1971). El Delta se convierte así en la despensa por excelencia de Barce- 
lona, «ejemplo de progreso agrario en nuestra región» (Mir, 1943: 193). Esta coyuntura es analizada por Deffontaines (1949) en su insuperado ensayo sobre la zona. La Guerra Civil trunca la vocación exportadora, pero refuerza los vínculos con Barcelona. En todo caso, la preponderancia cerealista de CT1955 (figura 6) debe considerarse más bien circunstancial y puede deberse en parte a la importancia alcanzada por los forrajes, dado que estos no figuran como clase estadística en CT1955.

En el caso del Maresme, ya hemos visto cómo en el siglo XIX se documentan cultivos hortícolas dirigidos hacia Barcelona e incluso hacia la exportación (sobre todo la patata). La figura 9 evidencia cómo las hortalizas se expanden por la estrecha franja litoral, aunque los cereales enmascaren parcialmente esta realidad (figura 6). Llobet (1955b) y Pomés (1991) explican que el aumento del regadío se debe a la generalización de las bombas de extracción accionadas mediante motor eléctrico, cuya difusión puede datarse durante la Primera Guerra Mundial. Llobet (1955b) comenta que la orientación exportadora se vigoriza en ese momento, sobre todo hacia Inglaterra. Nace de este modo la denominación Mataró potatoes aplicada a la patata tempranera del Maresme, cuyo momento álgido se sitúa entre 1926 y 1936 (Pomés, 1991). Durante la II República, en 1932-1934 se aprueba una normativa especial para las mismas, ${ }^{15}$ con voluntad de garantizar en el extranjero su origen y que incluye dispositivos sancionadores en caso de fraude, lo que puede ser interpretado claramente como un antecedente de las actuales políticas de denominación de origen (Paül, 2006). Asimismo, parece evidente que la producción tenía entonces carácter estratégico para España.

Más allá de las patatas, Llobet (1955b) da cuenta de otras orientaciones hortícolas del Maresme, algunas en competencia con el Delta del Llobregat y también destinadas a la exportación (la lechuga trocader), otras claramente de consumo en Barcelona. Entre estas últimas destacan dos particularidades: los fresones y las flores. En el primer tercio del siglo xx e incluso antes, se producían fresones en la franja regada costera del Maresme, pero, como se ha dicho, a partir de la década de 1960 se extienden de forma sistemática por antiguas viñas del Alt Maresme. En cuanto a las flores, se ha establecido su fecha de inicio comercial en 1922 en Vilassar de Mar, con la llegada de Beniamino Farina desde Italia y la creación de la primera explotación de claveles (Lleonart et al., 1981; Rosés, 1989). El modelo es rápidamente emulado $\mathrm{y}$, con posterioridad, complementado por tulipanes, rosas, etc. Sea como fuere, con la autarquía las producciones hortícolas del Maresme se destinan al mercado interior, lo que hunde la patata y refuerza otras hortalizas (figura 6).

Entre el Maresme y el Baix Llobregat, se sitúa el Barcelonès, con un área regada por el Rec Comtal que, como ya hemos dicho, actuaba como abastecedora de Barcelona (figuras 3 y 5). En el mapa que ahora nos ocupa, la figura 6, el uso dominante en tres municipios es, incluso en la coyuntura autárquica, las hortalizas de vocación netamente urbana. Los municipios a los que nos referimos son L'Hospitalet, Barcelona - que, en 1955, ya ha alcanzado sus dimensiones actuales, englobando nueve antiguos municipios y parte de otros tres - y Sant Adrià. Así, el predominio hortícola se afianza. Pero lo que la figura 6 no revela es el hecho de que los usos agrarios del suelo en este sector han sufrido ya una reducción mayúscula a causa de la urbanización; nos hemos referido a este proceso en Tort y Paül (2009), del que aportamos aquí las claves básicas. En 1859 se aprueba el Plan de Ensanche de Barcelona que, en términos generales, afecta primero a los secanos que a los regadíos de huerta, lo que da idea de la capacidad de resistencia de los segundos en términos de rentabilidad y explica que los viñedos o los cereales tengan una presencia baja en CT1955

15 «Ministerio de Agricultura, Industria y Comercio. Decretos», en Gaceta de Madrid, n 50 (19/2/1932), pp. 1228-1230; «Ministerio de Agricultura. Orden», en Gaceta de Madrid, nº 363 (29/12/1933), p. 2258; y «Ministerio de Agricultura. Orden», en Gaceta de Madrid, nº 115 (25/4/1934), p. 579. 
en Barcelona (60 y 770 ha, respectivamente). En CT1955 en Barcelona se contabilizan aún 1.583 ha de hortalizas, de las que unos dos tercios se corresponden con la actual Zona Franca (anexionada de L'Hospitalet) y un tercio con el área del antiguo Rec Comtal, lo que implica que la reducción en ese sector ha sido ya mayúscula, si tenemos en cuenta que la superficie regada en el ochocientos por este canal ultrapasaba las 1.300 ha (Martín, 1999). De hecho, la figura 7 evidencia claramente una reducción de los usos agrarios del suelo de AM1850 a CT1955 en los cinco municipios del actual Barcelonès, especialmente marcada en Barcelona y L'Hospitalet. La agricultura desparecerá definitivamente en el Pla de Barcelona en la década de 1960. En definitiva, en el momento de máxima vigorosidad de las agriculturas periurbanas del Baix Llobregat y del Maresme, sucumbe la del Barcelonès. Se trata del primer ocaso de la agricultura periurbana, que presagia otros.

Para finalizar este apartado resta por referirse a una actividad que está implícita en la figura 6, pero sobre la que no hemos reflexionado aún. Como hemos visto, existían vaquerías en el Delta del Llobregat desde finales del siglo XIX, pero perecen a principios del siguiente. En paralelo, emerge una zona de producción lechera en el Vallès Oriental, enraizada en una tradición mantequera, quesera y lechera que, desde Granollers y mediante la línea de tren inaugurada en 1854 (Font Garolera, 1999), se orientaba a Barcelona ya en una fecha tan temprana como 1874 (Garrabou y Planas, 1998). El consumo urbano de leche se generaliza a principios del siglo xx en Barcelona, coincidiendo con la reducción del consumo de pan (Ràfols, 2000; Cussó y Garrabou, 2006). De acuerdo con autores como Vila (1930), Giralt (1990) o Garrabou y Planas (1998) en el primer tercio del siglo $\mathrm{xx}$ en el Vallès se transforman campos de cereales en forrajes para vacas y se generaliza la producción lechera destinada a la capital. Muchos de los cereales de la figura 6 son en realidad forrajes porque CT1955 no los considera como uso. Mir (1943) fija claramente en plena posguerra que Barcelona depende de esta área del Vallès para su abastecimiento lechero. Llobet (1947) también comenta la inserción del Montseny en el circuito lechero con destino a la capital.

\section{Los usos agrarios del suelo en el último tercio del siglo $\mathrm{XX}$ y principios del XXI (I): las categorías de usos}

Esta parte final del artículo previa a las conclusiones aborda las últimas décadas, de $1 T 1973$ en adelante. En primer lugar, en este apartado 6 analizamos los mapas obtenidos mediante 1T1973 (figura 10) y CA1999 (figura 11). En segundo lugar, en el apartado 7 abordamos la dinámica de pérdida generalizada de suelos agrarios experimentada desde la década de 1950. En este sentido, las explicaciones sobre los usos agrarios que vamos a realizar a continuación, sin tener en cuenta su abultada disminución global, son insuficientes por sí mismas y pueden dar pie a una imagen errónea de la realidad. Así, este apartado 6 no se debe desvincular del siguiente.

Los autores que han estudiado la agricultura catalana en las últimas décadas (entre otros, Majoral, 1979, 2002, 2006; Pujol y Benelbas, 1989) subrayan la especialización de distintas áreas en producciones concretas, rastreable en los usos agrarios del suelo. La observación es pertinente, pero es evidente que en nuestra región de estudio no constituye más que la última fase de un proceso dilatado en el tiempo. En este sentido, la especialización espacial reciente supone la culminación de dinámicas a medio o largo plazo. Estrictamente en términos de predominancia de los usos del suelo, no existen grandes variaciones entre la figura 10 y la 11, a pesar de las casi tres décadas transcurridas, lo cual sorprende viniendo de una sucesión de mapas anteriores realizados con otras fuentes que, aun a sabiendas de que estaban más espaciados en el tiempo, presentaban diferencias muy notables los unos de 


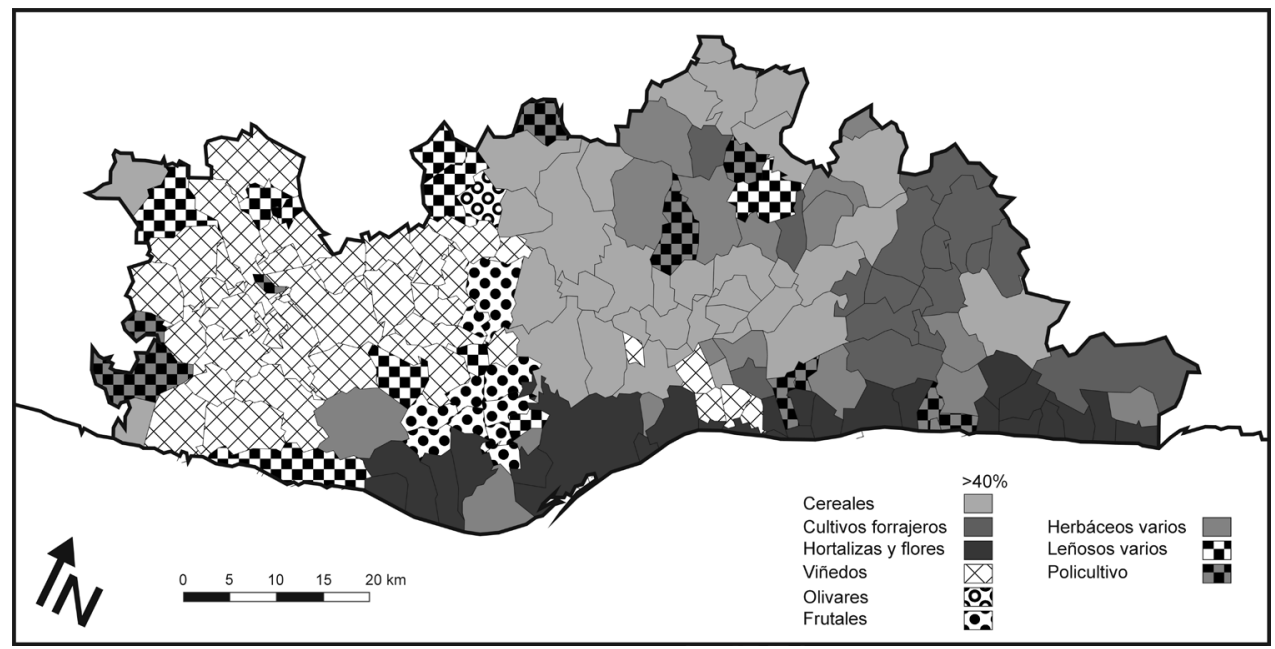

FiguRa 10. Preponderancia de usos agrarios del suelo en 1973.

Elaboración propia. Fuente: 1T1973.

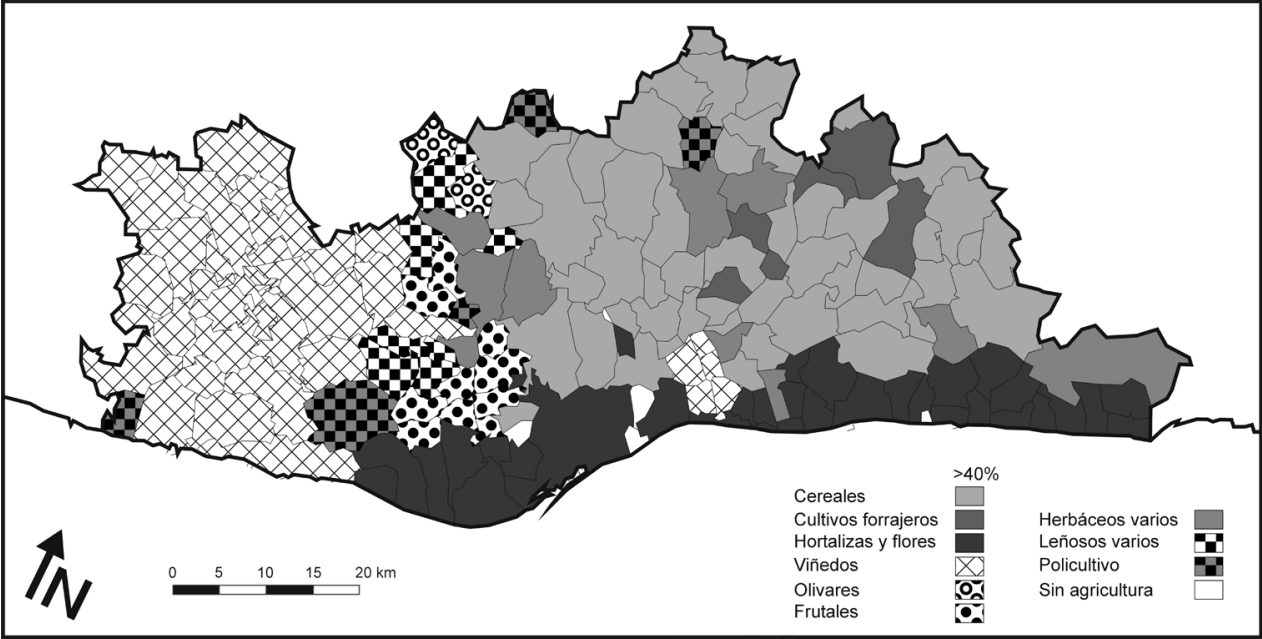

FiguRa 11. Preponderancia de usos agrarios del suelo en 1999.

Elaboración propia. Fuente: CA1999.

los otros. La principal diferencia entre las figuras 10 y 11 es el hecho de que en la primera la especialización está consolidándose y en la segunda es ya marcada. Así, en la primera aparecen muchos municipios con categorías mixtas (policultivo, herbáceos varios, leñosos varios), menos presentes en la figura 11. En otro orden de cosas, la figura 10 rompe con la sobrepresencia de cereales de la figura 6 que, como se ha dicho, era circunstancial. En este sentido, el mapa de la década de 1970 tal vez refleje mejor que el de la de 1950 la distribución de los usos agrarios del suelo del primer tercio del siglo XX. 
En este contexto, las dos figuras referidas evidencian algunas constantes que nos interesa subrayar. De entrada, la franja de hortalizas y flores en el litoral se percibe nítidamente, cubriendo los municipios costeros del Baix Llobregat, el Barcelonès y el Maresme. Sabemos que se han producido determinadas reconfiguraciones en esta orla litoral, por ejemplo el cambio de las flores en el sector de Vilassar de Mar y alrededores por la planta ornamental - lo que ha ido acompañado de la profusión de invernaderos en el área, que en la actualidad no son necesariamente agrarios, sino almacenes o tiendas. Otro cambio, ya anunciado en el anterior apartado, es la incorporación a esta franja hortícola de la producción de fresones en el Alt Maresme, allí donde antes había viñas, que se inicia en la década de 1960, alcanza su apogeo en las de 1970 y 1980 (Lleonart et al., 1981; Rosés, 1989), y que en la actualidad está en franca regresión ante la imposibilidad de competir con la producción andaluza y extracomunitaria. También detectamos la desaparición de la otrora dominante patata en el Maresme, aunque sea imperceptible para la cartografía por las categorías de usos empleadas. Pero en términos generales esta franja hortícola responde a la dinámica histórica acumulada y por lo tanto se dedica en lo fundamental al abastecimiento de hortalizas de la capital y del propio Maresme (sobre todo Mataró), en la actualidad una comarca netamente urbana. ${ }^{16}$ No obstante, este es el sector más directamente afectado por el proceso urbanizador y en este sentido hay por primera vez cinco municipios en 1999 (figura 11) que no registran estadísticamente agricultura, cuatro de los cuales están en la franja litoral: Badia del Vallès, Caldes d'Estrac, Esplugues, Sant Adrià y Santa Coloma.

En ambas cartografías aparece también un área con predominancia de frutales de clima templado, que como ya sabemos responde a dos lógicas: la Vall Baixa, dedicada a melocotones y ciruelos sobre todo; y las Muntanyes d'Ordal, a cerezos y melocotones de secano. La orientación urbana de estas producciones está fuera de dudas, aunque cabe mencionar su progresiva contracción. Asimismo, se mantiene el área de los olivares a los pies de Montserrat, que se convierte de este modo en el sector de mayor coherencia histórica del ámbito de estudio - ello a pesar de que, por efecto estadístico de la importancia que en esa zona también tiene el viñedo, los olivares aparezcan a veces camuflados mediante la categoría de leñosos varios. Existe alguna iniciativa reciente de revalorización del aceite del área de Olesa, pero en términos generales se trata de una producción en crisis. Por lo tanto, no existen buenos presagios para este uso del suelo, a pesar de que la baja intensidad cultural que requieren los olivos puede hacer mantener artificialmente esta categoría de uso en el tiempo.

En lo que se refiere al viñedo, se observa una concentración de este uso del suelo en las figuras 10 y 11 en las dos zonas con denominación de origen, Penedès/Cava y Alella. El establecimiento de las denominaciones de origen ha venido a reforzar las dinámicas preexistentes y ha permitido la aparición de nuevos productores que posibilitan el mantenimiento del uso del suelo, sobre todo en el primer caso; mientras, en el área de Alella se registra una reducción general de los viñedos, aunque sigan apareciendo como uso principal de varios municipios (Colomé, 2003; Saito y Takenaka, 2004; Molleví, 2007; Paül, 2011). El área de predominancia del viñedo en el Penedès en la figura 11 se corresponde

16 No es este el lugar para recrearse en esta cuestión, pero se trata de un asunto fundamental para entender el papel que desempeña esta agricultura en la región metropolitana, de ahí que no renunciemos a ofrecer algún dato al respecto. El 15\% de las hortalizas consumidas en Barcelona se producen en el Maresme y el Baix Llobregat, según datos de Mercabarna de 2007 (Paül, 2009). Como comparación, cabe decir que Andalucía y Francia aportan un $20 \%$ cada una. Sin embargo, en 1996 el Baix Llobregat y el Maresme suplían el 25\% del total, siendo entonces las principales suministradores del mercado central barcelonés, mientras que Andalucía aportaba en aquel momento el $20 \%$ y Francia, menos del 10\%. De este modo, a lo largo de la última década el Baix Llobregat y el Maresme han dejado de ser los principales abastecedores de alimentos frescos de Barcelona, pero aún así siguen representando un porcentaje significativo del aprovisionamiento urbano. 
casi a la perfección con el área demarcada por la denominación de origen. Como ya se ha indicado más arriba, el área de Martorell (norte del Baix Llobregat y extremo oriental del Alt Penedès) ha perdido su vocación vitícola, que ha substituido por una complejidad de usos reflejados en las cartografías que, en realidad, enmascara la práctica desaparición de la agricultura en el sector.

Finalmente, el Vallès se ha consolidado como el área cerealista de la región de estudio. En estos momentos el dominio de los cereales es prácticamente privativo de las dos comarcas vallesanas (figura 11). No obstante, conviene hacer dos matices. Por un lado, la extensión que, sobre todo en la figura 10, se observa de los cultivos forrajeros; se trata de un cultivo íntimamente relacionado con la aún notable presencia de ganado vacuno en este sector, sobre todo en el Vallès Oriental y, aunque la producción local de piensos es a todas luces insuficiente, ayuda en cierto modo a reducir los gastos en este concepto para las explotaciones. Por otro lado, la presencia de cereales como uso predominante en el Vallès, sobre todo en el Vallès Occidental - alrededor de grandes ciudades como Terrassa, Sabadell o Sant Cugat - tiene poco que ver con una dinámica histórica prolongada que haya cristalizado en una especialización concreta. Más bien se trata de un uso que responde a la presencia de unos pocos agricultores que cultivan muchas propiedades y que reciben a cambio el pago único de la PAC (Peix, 2009), lo que les permite sostenerse. En estos casos, el interés de los propietarios (no de los agricultores) es fundamentalmente especulativo, en una situación patente de rentas expectantes. Por otro lado, el predominio de hortalizas como uso agrario del suelo en el municipio de Ripollet (figura 11) tiene que ver con toda probabilidad con la existencia de huertos de ocio, y no con agricultura profesional.

\section{Los usos agrarios del suelo en el último tercio del siglo $\mathrm{xx} \mathrm{y}$ principios del $\mathrm{XXI}$ (II): la disminución de los suelos agrarios}

Como hemos referido más arriba, la explicación dada en el apartado anterior puede inducir a errores en el sentido de que la principal dinámica de los usos agrarios del suelo no ha sido su cambio interno, sino su disminución global. De entrada, es necesario detenerse en la cuestión de la variación general de los suelos agrarios, que resumimos en la tabla 2, pues es totalmente relevante para nuestro objeto de estudio; como se ha explicado en el apartado metodológico, la medimos siempre mediante las tierras labradas o cultivadas, no con la SAU, que induce a errores. No hay lugar a dudas con respecto al sentido de la dinámica imperante: la disminución. En los poco más de cincuenta años que separan 1955 de 2009 la reducción ha sido de un $-62 \%$, dicho de otro modo, en la actualidad sólo restan el $38 \%$ de los suelos agrarios existentes hace medio siglo. La disminución media ha sido del $1,15 \%$ anual, lo que equivale a unos $15 \mathrm{~km}^{2}$ por año. No obstante, la tabla 2 muestra una severa contracción hasta 1989 pero, a partir de entonces, el ritmo parece tender a aminorarse. Sin descartar problemas de recuento, y con las debidas cautelas, creemos que el freno a la pérdida de tierras agrarias de los últimos años puede estar debido a la consolidación de instrumentos rigurosos de ordenación territorial y planeamiento urbano que impiden la urbanización indiscriminada mediante grados variables de protección o gestión de determinados suelos agrarios. 
Tabla 2

EVOLUCIÓN DEL TOTAL DE TIERRAS CULTIVADAS

DE LA REGIÓN DE ESTUDIO (1955-56 - 2009)

\begin{tabular}{|c|c|c|c|}
\hline Año & Fuente & $\begin{array}{c}\text { Superficie } \\
\text { (ha) }\end{array}$ & $\begin{array}{c}\text { Variación anual media } \\
(\%)\end{array}$ \\
\hline $1955-56$ & CT1955 & 126.017 & $-1,94$ \\
\hline 1973 & $1 T 1973$ & 81.919 & $-1,23$ \\
\hline 1982 & CA1982 & 72.825 & $-2,92$ \\
\hline 1989 & CA1989 & 57.947 & $-1,16$ \\
\hline 1999 & CA1999 & 51.202 & $-0,81$ \\
\hline 2004 & $1 T 2004$ & 49.126 & $-0,47$ \\
\hline 2009 & CA2009 & 47.967 & \\
\hline
\end{tabular}

Elaboración propia.

Si ponemos estas cifras evolutivas en relación con la variación de los otros grandes tipos de usos del suelo para el conjunto del área de estudio (figura 12 y tabla 3), obtenemos que la pérdida de suelos agrarios tiene que ver sobre todo con la expansión de las zonas urbanas. De hecho, hacia 1998 por primera vez existen en la región de estudio más espacios urbanos que suelos agrarios cultivados. A pesar del aumento de los espacios urbanos, los sectores forestales no disminuyen, sino que se expanden (figura 12). De este modo, el único uso que puede estar asumiendo de forma generalizada el crecimiento urbano es el agrario. No podemos revisar aquí todos los estudios existentes sobre la evolución de la

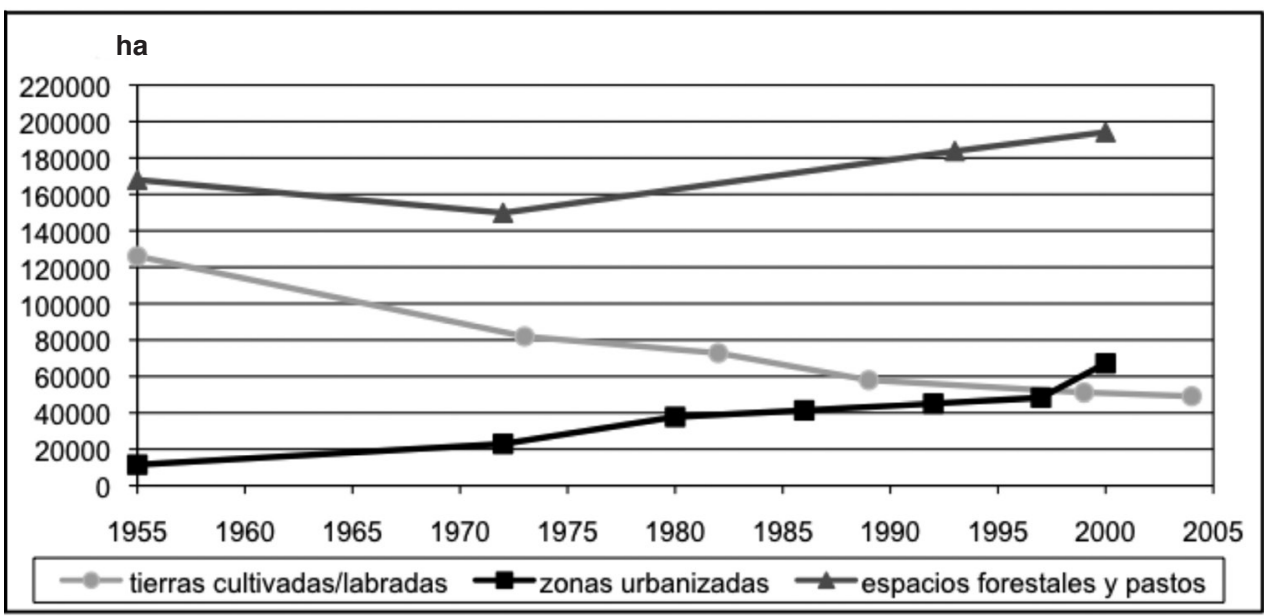

Figura 12. Aproximación a la evolución de los grandes tipos de usos del suelo de la región de estudio (1955-2004) mediante estadísticas diversas.

Elaboración propia. Fuentes: CT1955, 1T1973-2004, CA1982-1999, Inventari ecològic i forestal de Catalunya (1993), Solans (2002) e Ibàñez (2004). 
mancha urbana y su distribución territorial en la región de estudio (véanse Solans, 2002; Paül y Tonts, 2005; Font Arellano, 2006), pero creemos que queda explícita la causalidad. La tabla 3 complementa la figura 12, partiendo de la base de que es la única estadística que ofrecemos que proviene de teledetección y, por lo tanto, que las cifras no son comparables. Pero la tabla 3 permite comprobar que la dinámica negativa de los suelos agrarios obtenida mediante las estadísticas utilizadas es confirmada por teledetección.

Tabla 3

APROXIMACIÓN A LA EVOLUCIÓN DE LOS GRANDES TIPOS DE USOS DEL SUELO DE LA REGIÓN DE ESTUDIO MEDIANTE TELEDETECCIÓN (1987-2002)

\begin{tabular}{|l|r|r|r|r|r|}
\hline \multirow{2}{*}{ Gran tipo de uso del suelo } & \multicolumn{2}{|c|}{$\mathbf{1 9 8 7}$} & \multicolumn{2}{c|}{$\mathbf{2 0 0 2}$} & \multirow{2}{*}{ Variación } \\
\cline { 2 - 6 } & ha & \multicolumn{1}{c|}{$\%$} & \multicolumn{1}{c|}{ ha } & \multicolumn{1}{c|}{ \% } & 42,97 \\
\hline $\begin{array}{l}\text { Roquedos, arenales y } \\
\text { superficies acuáticas }\end{array}$ & $10.303,14$ & 3,18 & $14.730,74$ & 4,54 & \\
\hline $\begin{array}{l}\text { Recubrimiento ve- } \\
\text { getal (usos forestales } \\
\text { varios) }\end{array}$ & $186.581,01$ & 57,55 & $171.908,78$ & 53,03 & $-7,86$ \\
\hline Agrarios & $84.791,05$ & 26,16 & $69.511,46$ & 21,44 & $-18,02$ \\
\hline Urbanos & $42.508,08$ & 13,11 & $68.032,30$ & 20,99 & 60,05 \\
\hline
\end{tabular}

Cálculo mediante SIG de Cristina Perea (CCRS). Fuente: Classificació dels usos del sòl a Catalunya (1987 y 2002), elaborada a partir del LANDSAT-TM.

Si desagregamos la tendencia general apuntada para el casi medio siglo que va de 1955 a 1999 en los períodos 1955-1973 y 1973-1999 y la referimos a la escala municipal, obtenemos las figuras 13 y 14, respectivamente. En la figura 13, la cartografía pone de relieve una reducción generalizada de suelos agrarios en el entorno inmediato de Barcelona, en muchos municipios superior al $75 \%$ y, en la mayor parte de los casos, al 50\%. Se trata de una tendencia coherente con lo sucedido ya antes de 1955 en el municipio de Barcelona sobre todo, tal y como hemos visto más arriba, y que al fin y al cabo conlleva urbanizar por completo el llano barcelonés (Tort y Paül, 2009). Más allá de las pérdidas en Barcelona y su conurbación central, también se detectan reducciones superficiales notables en algunos municipios del Baix Vallès, que tienen que ver más con la construcción de grandes polígonos industriales que con la extensión residencial (caso, por ejemplo, del municipio de Montcada i Reixac). Municipios aislados de otras comarcas como Sant Andreu de la Barca, Vilanova i la Geltrú o Mataró, o buena parte del Vallès Occidental, del Baix Maresme y del Alt Maresme, también presentan reducciones de suelos agrarios bastante contundentes.

Algunos de estos municipios con altas disminuciones en la figura 13, por ejemplo en el Baix Maresme o en el Pla de Barcelona, tenían como cultivo principal las hortalizas y se destinaban al abastecimiento urbano. Cabe decir que estos usos estaban teóricamente protegidos mediante el conocido como «plan provincial» de 1959 y los «planes comarcales» del ámbito de Barcelona y entorno (1953), Baix Vallès (1961) y Baix Maresme (1963), ${ }^{17}$

17 Todos estos documentos se encuentran en el Arxiu de Planejament de la Direcció General d'Urbanisme de la Generalitat de Catalunya. Sus denominaciones completas son, respectivamente: «Plan General de Ordenación de la Provincia de Barcelona» (memoria de 1959 y normativa de 1963, aprobados por resolución de la Dirección General de Urbanismo, en BOE, n 102 (29/4/1963), pp. 7118-7119), «Plan de Ordenación de Barcelona y su 


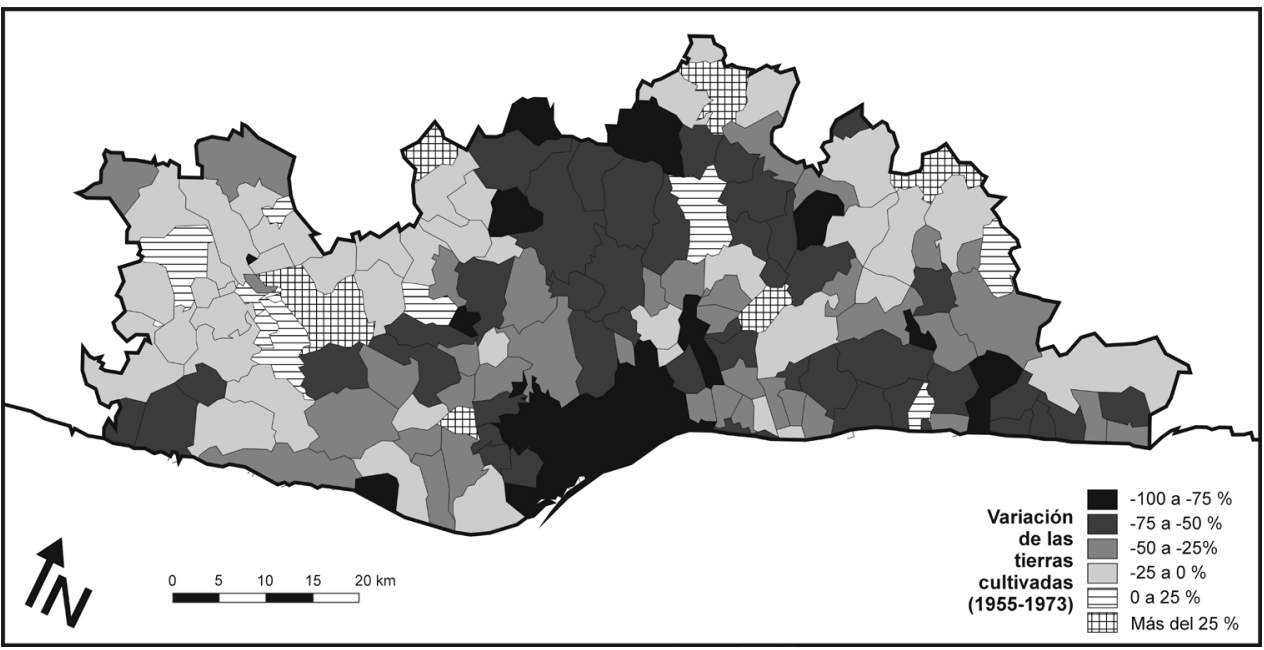

Figura 13. Evolución de las tierras cultivadas (1955-56 - 1973).

Elaboración propia. Fuentes: CT1955 y 1T1973.

que estipulaban en cada caso que en los secanos se podía urbanizar, pero que el regadío, en especial el de abastecimiento urbano, se debía reservar. De este modo, estamos ante un sonoro fracaso de la ordenación territorial franquista, que se suma a la imposibilidad de los planes urbanísticos municipales de la época - allí donde los hay - de dirigir el explosivo proceso de crecimiento urbano que se produce en especial a partir de la década de 1960 (Paül, 2006).

Asimismo, algunos municipios claramente de montaña presentan entre 1955 y 1973 reducciones importantes de superficie agraria, continuando con la lógica apuntada en la comparación AM1850-CT1955 (figura 7). Sabemos que algunos casos, por ejemplo en Sant Llorenç del Munt o en el Alt Maresme, tenían especialización en viñedo en CT1955, lo que indica una pérdida ante la falta de alternativas a ese cultivo en áreas de montaña, no causada por la urbanización, sino por el abandono. En cambio, en las Muntanyes d'Ordal las pérdidas superficiales en municipios como Cervelló o Corbera se deben al paso de campos, por lo general viñedos y otros leñosos de secano (cerezos), a urbanizaciones de segundas residencias, en especial en la década de 1960, a medida que se generaliza el uso del vehículo privado (Paül y Serrano, 2005). Aún así, en la figura 13 no presentan pérdidas superficiales agrarias e incluso crecen las tierras cultivadas en la mayoría de los municipios del Alt Penedès, que como ya se ha dicho en estos años transitan del cereal al viñedo, y de buena parte del Vallès Oriental, donde se está reforzando la integración agroganadera y la producción de forrajes (figura 10).

El último período analizado es 1973-1999 (figura 14). Cartografiamos hasta CA1999, dado que aún no se ha publicado el detalle municipal de CA2009 y que, como se ha dicho en el apartado metodológico, la fiabilidad de 1T2004 a escala municipal es muy baja, con

zona de influencia» (aprobado por Ley de 3 de diciembre de 1953, publicada en BOE, $\mathrm{n}^{\circ} 339$ (5/12/1953), pp. 7180-7181), «Plan Comarcal de Ordenación de Mollet, Martorellas, San Fausto de Campcentelles, La Llagosta y Santa Perpetua de Moguda» (consta aprobado por el Ministerio de Vivienda el 16/5/1961) y «Plan General de Ordenación del Sector Meridional de la Comarca del Maresme» (consta aprobado por el Ministerio de Vivienda el 4/3/1963, con normas complementarias aprobadas el 29/4/1966). 


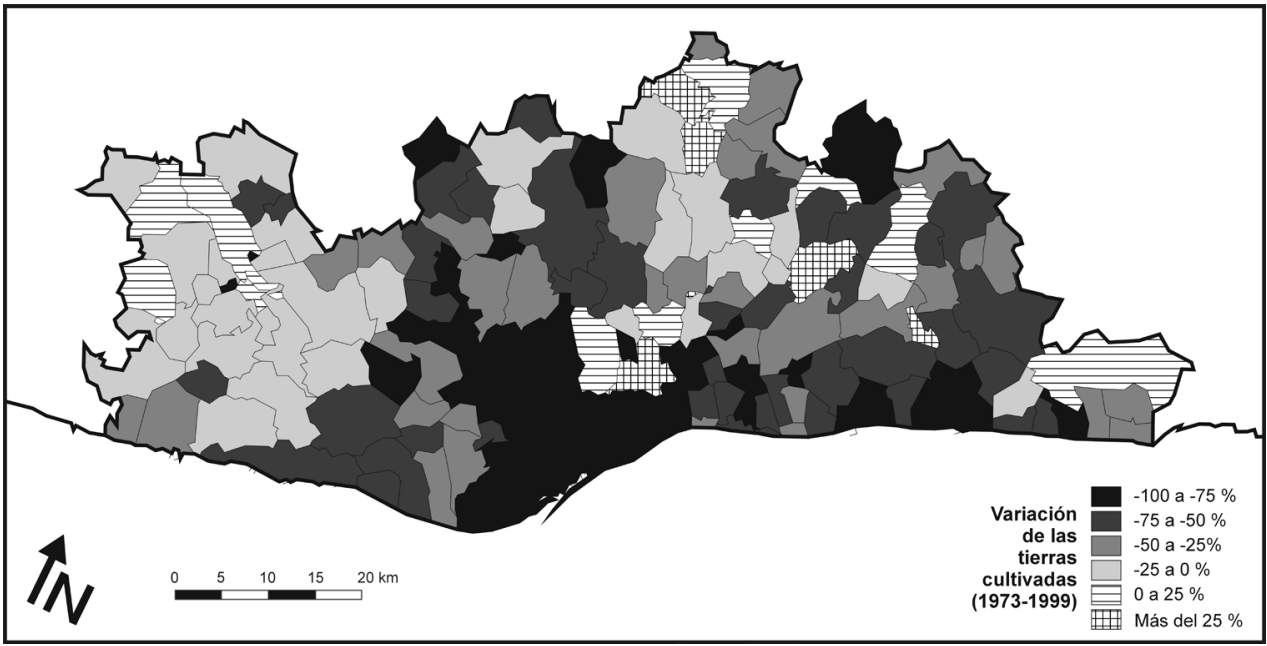

Figura 14. Evolución de las tierras cultivadas (1973 - 1999).

Elaboración propia. Fuentes: 1T1973 y CA1999.

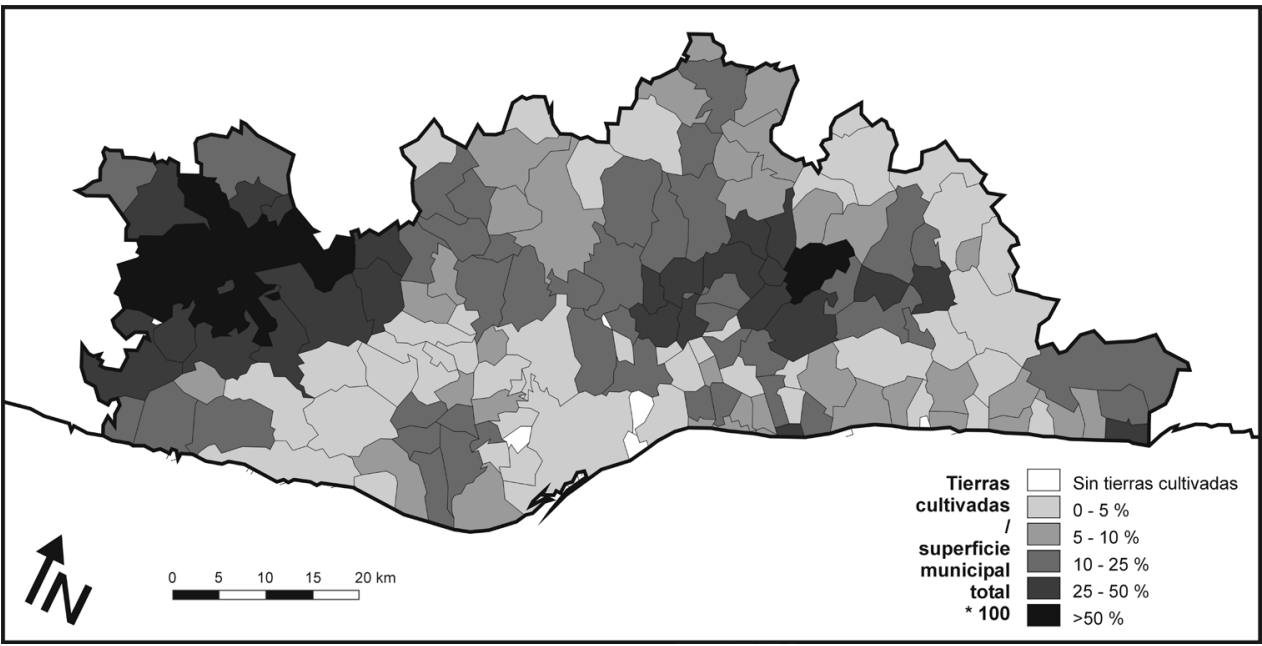

FIgURA 15. Porcentaje de las tierras cultivadas respecto al total de superficie municipal en 1999.

Elaboración propia. Fuente: CA1999.

resultados erráticos. En la figura 14 la conurbación de Barcelona sigue encabezando la disminución de los suelos agrarios, pero también aparecen otros municipios con pérdidas porcentuales muy altas, en especial en el Baix Llobregat, el Maresme y el Vallès Occidental, debiéndose tales reducciones a crecimientos residenciales e industriales y a la construcción de grandes infraestructuras. Si acumulamos las reducciones superiores al $-75 \%$ en las figuras 13 y 14 que afectan a varios municipios de Barcelona y entorno, obtenemos que 
muchos términos municipales han perdido casi por completo la agricultura y en este sentido la predominancia de usos de la figura 11 no tiene significación alguna en el paisaje. De hecho, en la figura 11 aparecen ya cinco municipios sin usos agrarios del suelo, tres de los cuales en la conurbación central. En efecto, tal y como se puede comprobar en la figura 15, la agricultura se puede dar por extinguida en Barcelona y cercanías inmediatas, así como en varios municipios del Maresme, del Baix Llobregat y del Vallès Occidental.

En la medida en que buena parte de estas reducciones en Barcelona y entorno inmediato se han producido después de 1973 (figura 14), se puede sostener que ha sido el planeamiento urbanístico gestionado en el período democrático el que las ha vehiculado (Paül, 2006, 2009). Esta afirmación es harto compleja y es imposible desarrollarla aquí, pero se puede concretar en el área cubierta por el Plan General Metropolitano (PGM) de 1976, aún vigente hoy en día. ${ }^{18}$ Según 1T1973, había en el área PGM 10.804 ha cultivadas, de las que 4.256 de regadío, sobre todo dedicadas a hortalizas; de ellas, el PGM protege 2.817 ha (las zonas con clave 24, «suelo rústico protegido de valor agrícola»). Más de treinta años después, estas 2.817 son las que no se han urbanizado o transformado en otros usos y, en términos generales, se corresponden con el actual Parc Agrari del Baix Llobregat, desarrollado urbanísticamente mediante un plan especial aprobado en 2004. ${ }^{19}$ De hecho, en la figura 15 dentro del continuo central urbano el núcleo que se mantiene con presencia porcentual relativamente alta de suelos agrarios es el del Parc Agrari, con municipios como Sant Boi o Viladecans. En definitiva, es el urbanismo el que ha facultado la desaparición de tierras cultivadas y los usos agrarios que quedan son los que los distintos planes urbanísticos han decidido.

Otro ámbito que sufre pérdidas evidentes en la figura 14 son las montañas: Ordal, Garraf, Montseny, etc. En realidad, en los municipios montanos la disminución de tierras labradas tiene que ver con dos casuísticas, como ya comentábamos antes. Por un lado, la construcción de urbanizaciones, inicialmente de segundas residencias, hoy en día en muchas ocasiones residencias principales (Vallirana, Corbera, Matadepera, etc.). Por el otro, el abandono de los campos y la progresión de la aforestación (Tagamanent, Aiguafreda, Òrrius, etc.). Esta segunda tesitura se ha producido en parte dentro de perímetros de parques naturales u otro tipo de espacios protegidos, de modo que estos están actuando como un desincentivo a la continuidad de las actividades agrarias o, al menos, sus políticas al respecto - cuando existen - no están siendo efectivas a la hora de evitar que la agricultura desaparezca. Esto es así a pesar de que esta pérdida produce una evidente reducción de la biodiversidad y complica la prevención de incendios.

Del análisis conjunto de las figuras 14 y 15 se puede inferir que las reducciones de tierras cultivadas afectan menos al Alt Penedès y al Vallès Oriental, coincidiendo en parte con aquellos municipios en los que las tierras labradas retienen mayor importancia superficial. En este sentido se puede afirmar que los territorios más alejados de Barcelona padecen menor expansión urbana, a pesar de que cabría matizar esta aseveración con datos posteriores a 1999. De todos modos, si correlacionamos estas constantes con las preponderancias de usos (figura 11), deducimos que son sectores de viñedos y cereales que no tienen nada que ver con el canon de la agricultura periurbana de abastecimiento de mercado urbano. En el caso del Alt Penedès en la década de 2000, el mantenimiento de la superficie agraria se debe en buena medida a una reivindicación sostenida de la so-

18 Cubre 27 municipios centrales del área metropolitana, más Les Botigues de Sitges (Sitges). El texto aprobado el 14/7/1976 fue publicado íntegramente por la Corporación Metropolitana de Barcelona (1976). El libro de Serratosa (1979) constituye una edición crítica del documento finalmente aprobado.

19 «Edicte de 12 d'agost de 2004, sobre acords de la Comissió Territorial d'Urbanisme de Barcelona referents al Parc Agrari del Baix Llobregat», en DOGC nº 4216 (10/9/2004), pp. 16582-16592. 
ciedad civil a favor de su preservación, ante la percepción de una creciente proliferación de proyectos industriales en la comarca. Al fin y al cabo, la movilización ha sido capaz de revertir el planeamiento expansivo heredado e implantar una protección para los viñedos. ${ }^{20}$ Así pues, la agricultura del Alt Penedès es periurbana en tanto que afectada por la presión urbanística, pero presenta unas lógicas muy distintas al modelo clásico thüniano de las hortalizas o el cinturón lechero.

\section{Discusión y conclusiones}

La revisión efectuada a lo largo del artículo permite comprobar una heterogeneidad sorprendente de usos agrarios del suelo para un ámbito territorial relativamente restringido, de poco más de $3.000 \mathrm{~km}^{2}$, diversidad que se incrementa si tenemos en cuenta la variación temporal durante el período de estudio. La multiplicidad agraria es consustancial al mundo mediterráneo (Mazurek y Blanchemanche, 1992; Tello, 1999; López Ontiveros, 2003), pero no se pueda obviar la fuerza de cambio que imprime la ciudad de Barcelona a la agricultura regional. Tal y como hemos visto en el apartado teórico inicial, la influencia urbana directa es característica de toda agricultura periurbana (Bryant y Johnston, 1992; Audirac, 1999; Thomas y Howell, 2003; Chaléard y Charvet, 2004). Para resumir gráficamente la complejidad abarcada, en la figura 16 esquematizamos la evolución espaciotemporal de los usos agrarios del suelo para los distintos subámbitos considerados, junto con el avance urbano entendido en un sentido amplio (zonas residenciales, polígonos industriales, infraestructuras, etc.). Pero no se puede perder de vista, ni para este esquema ni para el conjunto del artículo, que nos referimos a grandes tendencias y que muchas interpretaciones efectuadas pueden no ser acertadas, dada la escala de trabajo escogida y las dificultades metodológicas aludidas. En este sentido, estamos de acuerdo con un autor que estudió los usos agrarios del suelo del conjunto de la provincia de Barcelona a mediados del siglo xx cuando afirmaba lo siguiente:

«[P] ara cada tipo de aprovechamiento y en lo que se refiere a la extensión que se le destina en la provincia, las cifras iniciales y finales indicadas señalan una tendencia determinada, bien definida; pero [...] tal tendencia casi nunca se ha manifestado de una manera uniforme. Los cultivos que acusan más marcada tendencia a disminuir no dejan de tener sus zonas en las que todavía se han incrementado, y viceversa, los cultivos que más tienden a incrementarse $[\ldots]$ no dejan de tener asimismo zonas en las que su importancia, por una causa u otra ha decrecido» (Llovet, 1948: 78).

Sistematizando las transformaciones estudiadas, se pueden describir tres grandes dinámicas de cambio que han actuado en el territorio analizado a lo largo del tiempo, modificando los usos agrarios del suelo: la inserción de la agricultura regional en marcos geoeconómicos extrarregionales, la conformación y evolución de un modelo agrario periurbano en el sentido estrictamente thüniano y, en última instancia, el crecimiento urbano. Pensamos que tiene interés desarrollarlas en estas conclusiones. La primera dinámica se rastrea sobre todo

20 «Pla director territorial de l'Alt Penedès», aprobado el 16/9/2008 (DOGC, n ${ }^{\circ} 5241$ (22/10/2008), pp. 77078-77130), después de un largo proceso de elaboración. Incluye una normativa contundente para el declarado como «suelo de protección especial de la viña». En la comarca hay unas 28.000 ha de viñedos y el «suelo de protección especial de la viña» cubre unas 24.000. El plan en sí mismo fue reclamado por la sociedad civil para superar el planeamiento individual de los 27 municipios, juzgado como desarrollista, y las administraciones se vieron obligadas a elaborarlo y tramitarlo (Paül, 2006). Cabe decir que estas determinaciones para con las viñas han sido confirmadas en el «Pla territorial metropolità» aprobado el 20/4/2010 (DOGC, $\mathrm{n}^{\circ} 5627(12 / 5 / 2010)$, pp. 36855-36945). Este plan está vigente para el Alt Penedès, como para el resto de la región, pero la reciente Llei 23/2010 (citada en el apartado metodológico) supone la redacción ulterior de un plan territorial propio para el flamante ámbito de planificación del Penedès. 


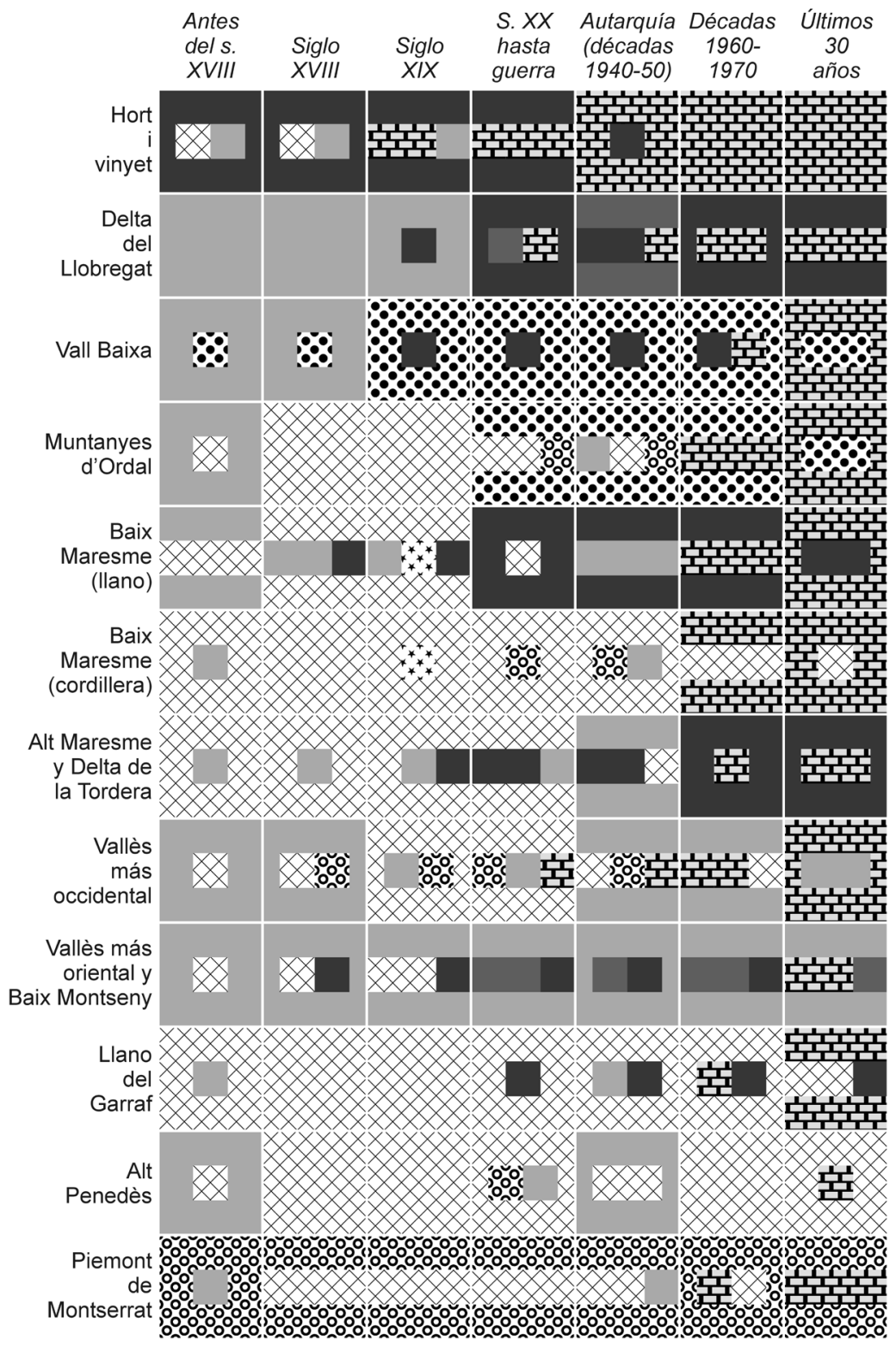

$\begin{array}{lll}\text { Cereales } & \square \text { Vinedos } \\ \text { Cultivos forrajeros } & \text { Olivares y frutos secos } \\ \text { Hortalizas y flores } & \text { Frutales de clima templado } \\ \text { Zonas urbanizadas } & \text { Naranjales }\end{array}$

FiguRa 16. Esquema, por subámbitos de la región de estudio, de la dinámica espaciotemporal de los usos agrarios del suelo y de la urbanización.

Elaboración propia. 
en el crecimiento del viñedo desde el siglo XVIII y durante el XIX, inicialmente a partir del comercio del aguardiente, pero después con otras opciones (vino y, más tarde, cava). El viñedo no se entendería sin el traslado de los productos vinícolas derivados hacia fuera de la región de estudio, por lo que las fuerzas de mercado extrarregionales explican su progresión y, en la práctica, su replantación parcial una vez que la filoxera esquilma a las cepas. Asimismo, también se debe insertar en lógicas extrarregionales el aumento circunstancial que experimentan los cereales en la autarquía posterior a la Guerra Civil, pues responde a decisiones tomadas desde instancias gubernamentales y a una coyuntura de extraordinaria carestía y, como dejó bien escrito Llobet (1947 [Reed. 1990]: 242), fuera de la situación «normal del mercado». Así pues, el impulso vitícola y la breve expansión cerealista de las décadas de 1940 y 1950 se pueden interpretar en clave de la inclusión de la región en marcos geoeconómicos más amplios.

La segunda dinámica responde plenamente a los postulados thünianos clásicos. Hemos visto cómo existía una modesta horticultura asociada al Rec Comtal y muy próxima a la ciudad desde antes del período de estudio, pero es sobre todo desde finales del xviII y durante el siglo y medio posterior cuando se conforma una verdadera agricultura periurbana y ésta alcanza su clímax. Los dos usos agrarios próximos a las ciudades teorizados por von Thünen se encuentran en la región de estudio: las hortalizas y los forrajes del cinturón de la leche. Y, tal y como postulan autores posteriores a von Thünen, se desplazan en el espacio con el paso del tiempo (Bryant y Johnston, 1992). De este modo, la producción lechera empieza en la propia ciudad de Barcelona y en el Delta del Llobregat (Ràfols, 2000), pero acaba asentándose en el Vallès Oriental, con un incremento asociado de los cultivos forrajeros. Y la horticultura se extiende desde el hort $i$ vinyet por tierras del Baix Llobregat y el Maresme, hasta conformar una franja hortícola litoral que se percibe muy bien en los mapas de usos agrarios del suelo de 1T1973 y CA1999 (figuras 10 y 11), aunque ya en un momento en el que dominan ciertamente los usos urbanos en esos municipios costeros.

Tal vez lo más sorprendente de la agricultura periurbana barcelonesa es la heterogeneidad local y comarcal que alcanzan las producciones hortofrutícolas, quizás más allá de lo esperable en el seno de la promiscuidad mediterránea. Contamos al menos con las hortalizas litorales en su inherente diversidad (alcachofas en el Delta, fresones en el Alt Maresme, etc.), los frutales de la Vall Baixa (melocotoneros y ciruelos principalmente), los frutales de Ordal (cerezos y melocotoneros de secano sobre todo, recuérdese que como reconversión de antiguos viñedos) y la floricultura en el Baix Maresme - una producción, esta última, que no es alimentaria, lo que confirma alguno de los supuestos teóricos planteados al inicio del artículo. No hemos encontrado en la literatura disponible un caso comparable en términos de heterogeneidad. De aquí surge una posible línea de investigación futura, ¿es la región barcelonesa excepcional?

La tercera dinámica consiste en el crecimiento urbano que, en nuestro caso, se produce por norma en suelos agrarios. Intentando evitar la «narrativa negativa» a la que aludíamos en la introducción de autores como Benfield et al. (1999), hemos analizado el patrón de las pérdidas agrarias, especialmente acuciantes en el último medio siglo, a pesar de que haya antecedentes como la urbanización del Pla de Barcelona. Si la primera influencia de la ciudad en su campo circundante consiste en la generación de cinturones agrarios periurbanos de geometrías variables, la segunda es su progresiva fagocitación. En la actualidad no se trata únicamente, como a veces se arguye de forma simplista, de crecimientos residenciales de bajas densidades, sino también de polígonos industriales, de urbanizaciones en bolsas dispersas, de infraestructuras, etc. El mosaico resultante es complejo y en estos momentos tiene que ver en buena medida con la ordenación territorial, por ejemplo cuando 
con ella se deciden proteger suelos agrarios y esa protección es efectiva (Parc Agrari del Baix Llobregat o los «suelos de protección especial de la viña» en el Alt Penedès), ya que es entonces cuando los usos agrarios parecen mantenerse. Pero también puede resultar que la ordenación (incluyendo el planeamiento urbanístico) promueva la desaparición de dichos usos, o bien que los proteja pero tal protección no se respecte, como sucedió en el franquismo. Y tampoco se puede perder de vista el rol ambiguo de los espacios naturales protegidos con la agricultura que se encuentra en su seno.

Tal y como se reflejaba en el marco teórico, determinados usos agrarios o paraagrarios aparecen asociados a la urbanización e incrementan la diversidad de los ya de por sí variados usos agrarios del suelo. Es el caso del baldío social preconizado por la teoría de la anticipación, que, a pesar de la dificultad de detectarlo por su habitual grano fino, hemos podido describir en los cereales del Vallès Occidental; posiblemente también se dé en los olivares del Pla de Montserrat, donde, aunque se mantienen los árboles, el abandono es patente. También los huertos de ocio forman parte de este grupo de usos heterogéneos; mediante CA1999 hemos apuntado que se encuentran en Ripollet, pero sabemos que ocupan buena parte del regadío de Vilanova - donde, dicho sea de paso, se detecta un proceso general de horsification como el aludido en la bibliografía, de igual modo que en algunas fincas del Parc Agrari del Baix Llobregat. Un uso paraagrario en particular que hemos observado son los invernaderos para planta ornamental de Vilassar de Mar o Premià de Mar, que se emplean más como almacén o tienda que como lugar de producción.

En el actual contexto existen múltiples motivos estratégicos para no perder más tierras cultivadas en nuestro país, empezando por su función básica de producción de alimentos (Paül, 2009). Esta necesidad de plantearse que no se produzcan más mermas agrarias es especialmente acuciante en casos de suelos de calidad agronómica alta, con irrigación garantizada, que han sido objeto de un esfuerzo cultural continuado, que se encuentran próximos a mercados urbanos con los que mantienen vínculos directos y que dan lugar a producciones individualizables. Estas circunstancias se reúnen en la región de estudio. El recientemente aprobado y largamente ansiado plan territorial metropolitano, citado en el apartado 7, tiende a reforzar la protección de lo ya protegido por el planeamiento urbanístico, a pesar de que deja abierta la puerta para futuras desclasificaciones en algunos lugares. En términos generales es un marco aceptable, que no debería convertirse una vez más, como en tantas otras ocasiones en ordenación territorial, en papel mojado por la razón que sea. Y no hay demasiado margen para abstraerse del asunto: en 1998 la primera propuesta conocida de plan territorial metropolitano - no aprobada - blindaba 57.521 ha como protegidas agrarias. De acuerdo con la tabla 2, existen hoy en día ya 10.000 ha menos.

\section{Agradecimientos}

A Pablo Giménez, por la oportunidad y por las atinadas observaciones al manuscrito original. A Sabela Labraña, a Josep Montasell y a Juan Manuel Trillo, por su concienzuda lectura de la primera versión del artículo. A David Serrano, por la ayuda en la dilatada confección de la base de datos de AM1850. A Juan F. Ojeda, Enric Tello, Joan Tort y Luis Urteaga, por los comentarios críticos realizados al capítulo correspondiente de la tesis, tenidos activamente en cuenta para este artículo. En todo caso, los errores y las omisiones no son atribuibles a estas personas, sino a mí exclusivamente. 


\section{Referencias}

ARAKI, H. (2005): «Domestic Food Supply System and Rural Sustainability: Comparative Study of South Korea's and Japan's Fruit and Vegetable Supply». En A.S. Mather (Ed.), Land Use and Rural Sustainability. University of Aberdeen. Aberdeen, pp. 47-51.

AUDIRAC, I. (1999): «Unsettled views about the fringe: rural-urban or urban-rural frontiers?». En O.J. Furuseth y M.B. Lapping (Eds.), Contested Countryside: The Rural Urban Fringe in North America. Ashgate. Aldershot, pp. 7-32.

BARBA, M. (1789): $s . n$. Texto inédito en origen. Edición: SABATÉ, A. (Ed.) (1991): El corregiment i partit de Vilafranca del Penedès a l'últim terç del segle XVIII. Respostes al qüestionari de Francisco de Zamora de Manuel Barba i Roca. Museu de Vilafranca. Vilafranca del Penedès, 88 pp.

BARROS, C. (2006): «La ciudad en el campo: nuevas ruralidades y lugares rururbanos». En J. Nogué y J. Romero (Eds.), Las otras geografías. Tirant lo Blanc. València, pp. 325-338.

BASSEGODA, P.-J. (1971): Huerto y viñedo de Barcelona (La guerra de los laudemios). Contribución al estudio de la Historia del Urbanismo de la Ciudad Condal. Escuela Técnica Superior de Arquitectura de Barcelona. Barcelona, 206 pp.

BENFIELD, F.K., RAIMI, M.D. y CHEN, D.D.T. (1999): Once There Were Greenfields. How Urban Sprawl is Undermining America's Environment, Economy and Social Fabric. Natural Resources Defense Council/Surface Transportation Policy Project. New York/Washington, $224 \mathrm{pp}$.

BOADA, M. y SAURÍ, D. (2002): El canvi global. Rubes. Barcelona, 143 pp.

BOISMENU, A. de (2004): La fin des paysages? Livre Blanc pour une gestion ménagère de nos espaces ruraux. Fédération Nationale des SAFER. Paris, $47 \mathrm{pp}$.

BOMANS, K. et al. (2010): «Underrated transformations in the open space - The case of an urbanized and multifunctional area», en Landscape and Urban Planning, $\mathrm{n}^{\circ}$ 94, pp. 196-205.

BRYANT, C.R. y JONHSTON, T.R.R. (1992): Agriculture in the City's Countryside. University of Toronto Press. Toronto, $233 \mathrm{pp}$.

BRYANT, C.R., RUSSWURM, L.H. y MCLELLAN, A.G. (1982): The city's countryside. Land and its management in the rural-urban fringe. Longman. Harlow, $249 \mathrm{pp}$.

BURGUEÑO, J. (2007): «Cartografia cadastral de la província de Lleida (segles XVIIIXIX)». En: La cartografia cadastral a Espanya (segles XVIII-XIX). Institut Cartogràfic de Catalunya. Barcelona, pp. 39-49.

BURGUEÑO, J. y LASSO, F. (2003): Història del mapa municipal de Catalunya. Generalitat de Catalunya. Barcelona, $192 \mathrm{pp}$.

BUSQUETA, J. (1991): Una vila del territori de Barcelona: Sant Andreu de Palomar als segles XIII $i$ XIV. Fundació Salvador Vives i Casajuana. Barcelona, 366 pp.

CALLAU, S., ISLA, E. y PAÜL, V. (2008): «El SIGAT, un sistema d'informació geogràfica per al Parc Agrari del Baix Llobregat», en Treballs de la Societat Catalana de Geografia, $\mathrm{n}^{\circ} 65$, pp. 522-536.

CAMARERO, C. (2007): «La cartografía de los catastros españoles del siglo XVIII». En: La cartografia cadastral a Espanya (segles XVIII-XIX). Institut Cartogràfic de Catalunya. Barcelona, pp. 21-37.

CANET, I. y SEGURA, A. (Coords.) (1988): El Catastro en España. De 1906 a la época actual. Lunwerg/Ministerio de Economía y Hacienda. Barcelona/Madrid, 212 pp.

CAPEL, H. (1999): «El Rec Comtal de Barcelona y otros canales mediterráneos», en Biblio 3W. Revista Bibliográfica de Geografía y Ciencias Sociales, $\mathrm{n}^{\circ}$ 157, 12 pp. Disponible en: <http://www.ub.edu/geocrit/b3w-157.htm> (Acceso 25-7-2011). 
CHALÉARD, J.-L. y CHARVET, J.-P. (2004): Géographie agricole et rurale. Belin. Paris, $240 \mathrm{pp}$.

CHISHOLM, M. (1962): Rural Settlement and Land Use. Hutchinson University Library. London, $183 \mathrm{pp}$.

CODINA, J. (1971): El Delta del Llobregat $i$ Barcelona. Gèneres i formes de vida dels segles XVI al XX. Ariel. Barcelona, 478 pp.

CODINA, J. (1995): «El Baix Llobregat, 1750-1850: un segle transcendent». En: À. Calvo (Ed.), El pas de la societat agrària a industrial al Baix Llobregat. Agricultura intensiva $i$ industrialització. Publicacions de l'Abadia de Montserrat. Barcelona, pp. 109-148.

COLOMÉ, J. (Coord.) (2003): De l'aiguardent al cava. El procés d'especialització vitivinícola a les comarques del Penedès-Garraf. El 3 de Vuit. Vilafranca del Penedès, 323 pp.

CORPORACIÓN METROPOLITANA DE BARCELONA (1976): Plan general metropolitano de ordenación urbana de la Entidad Municipal Metropolitana de Barcelona. Corporación Metropolitana de Barcelona. Barcelona, 4 vol.

CUSSO, X. y GARRABOU, R. (2006): «Els sistemes alimentaris: una dilatada transició». En: R. Garrabou (Coord.), Història Agrària dels Països Catalans. Segles XIX-XX. Fundació Catalana per a la Recerca i la Innovació. Barcelona, pp. 433-464.

DANTÍ, J. (2008): «Els cereals. Retrocés del guaret i conreus intensius». En: E. Serra (Coord.), Història Agrària dels Països Catalans. Edat Moderna. Fundació Catalana per a la Recerca i la Innovació. Barcelona, pp. 91-124.

DARP (2000): Estadístiques Agràries i Pesqueres de Catalunya 1999. Departament d'Agricultura, Ramaderia i Pesca. Barcelona, 283 pp.

DEFFONTAINES, P. (1949): «Le Delta del Llobregat. Étude de géographie humaine», en Revue Géographique des Pyrénées et du Sud-Ouest, no 20(3-4), pp. 138-174.

DONADIEU, P. (1998): Campagnes urbaines. Actes Sud/École Nationale Supérieure du Paysage. Arles, $200 \mathrm{pp}$.

DRESCHER, A.W. (2001): Urban and Peri-urban Agriculture. A briefing guide for the successful implementation of Urban and Peri-urban Agriculture in Developing Countries and Countries of Transition. FAO. Roma, 84 pp. Disponible en: <http://www.fao.org/ fileadmin/templates/FCIT/PDF/briefing_guide.pdf> (Acceso 20-7-2011).

FERNÀNDEZ, J. (1989): «Aprofitaments comunals, prats i pastures al delta del Llobregat (segles XIV-Xv). Conflictes per la utilització de l'espai a la Baixa Edat Mitjana», en Acta historica et archaeologica mediaevalia, $\mathrm{n}^{\circ} 10$, pp. 189-220.

FERNÀNDEZ, J. (1993): «Les ordinacions municipals i la protecció de la viticultura en l'antic territori de Barcelona (s. XIV-XVI)». En: E. Giralt (Coord.), Vinyes $i$ vins: mil anys d'història. Universitat de Barcelona. Barcelona, vol. II, pp. 315-326.

FLEURY, A. y DONADIEU, P. (1997): «De l'agriculture péri-urbaine à l'agriculture urbaine», en Le Courrier de l'Environnement de l'INRA, n 31, 15 pp.

FONT ARELLANO, A. (Dir.) (2006): Transformacions urbanitzadores 1977-2000. Àrea metropolitana i regió urbana de Barcelona. Mancomunitat de Municipis de l'Ârea Metropolitana de Barcelona. Barcelona, $164 \mathrm{pp}$.

FONT CASASECA, N. (2008): «La cartografia parcel-lària del vuit-cents com a font d'anàlisi per conèixer el paisatge històric: Sant Martí de Provençals (1853-1871)», en Treballs de la Societat Catalana de Geografia, nº 65, pp. 383-392.

FONT GAROLERA, J. (1999): La formació de les xarxes de transport a Catalunya (17611935). Oikos-tau. Vilassar de Mar, 454 pp.

GALLENT, N. y ANDERSSON, J. (2007): «Representing England's rural-urban fringe», en Landscape Research, $\mathrm{n}^{\circ} 32(1)$, pp. 1-21. 
GANT, R.L., ROBINSON, G.M. y FAZAL, S. (2011): «Land-use change in the "edgelands': Policies and pressures in London's rural-urban fringe», en Land Use Policy, $\mathrm{n}^{\circ}$ 28, pp. 266-279.

GARCIA ESPUCHE, A. (1998): Un siglo decisivo. Barcelona y Cataluña 1550-1640. Alianza. Madrid, 511 pp.

GARCIA RAMON, M.D. (1976): «Valor actual del modelo de Von Thünen y dos comprobaciones empíricas», en Revista de Geografía, n 10(1-2), pp. 11-33.

GARRABOU, R. y PLANAS, J. (1998): Estudio Agrícola del Vallés (1874). Museu de Granollers. Granollers, $287 \mathrm{pp}$.

GARRABOU, R. y PUJOL, J. (1988): «La especialización de la agricultura mediterránea y la crisis. Cataluña y el País Valenciano». En: R. Garrabou (Ed.), La crisis agraria de fines del siglo XIX. Crítica. Barcelona, pp. 94-130.

GARRABOU, R., CUSSÓ, X. y TELLO, E. (2007): «La persistència de conreu de cereals a la província de Barcelona a mitjan segle XIX», en Estudis d'història agrària, n 20, pp. 165-221.

GIL, P. (1599): Libre primer de la historia Cathalana en lo qual se tracta de Historia o descripció natural, ço es de cosas naturals de Cathaluña. Texto inédito en origen. Edición: IGLÉSIES, J. (Ed.) (2003): Pere Gil (1551-1622) i la seva Geografia de Catalunya. Societat Catalana de Geografia. Barcelona, $329 \mathrm{pp}$.

GIMÉNEZ, I. (2004): La transformació del paisatge del Masnou (1849-1945). Ajuntament del Masnou. El Masnou, 152 pp.

GIRALT, E. (1950): «Evolució de l'agricultura al Penedès». En: Actas y comunicaciones de la I ${ }^{a}$ Asamblea Intercomarcal de Investigadores del Penedès y Conca d'Òdena. Igualada Bas. Martorell, pp.166-176.

GIRALT, E. (1952): «La viticultura y el comercio catalán del siglo XVIII», en Estudios de Historia Moderna, $\mathrm{n}^{\circ}$ 2, pp. 159-176.

GIRALT, E. (1990): «L'agricultura». En: J. Nadal (Dir.), Història econòmica de la Catalunya contemporània. Enciclopèdia Catalana. Barcelona, vol. 2, pp. 121-305.

GIRALT, E. (2008): «La vinya i el vi durant l'edat moderna». En: E. Serra (Coord.), Història Agrària dels Països Catalans. Edat Moderna. Fundació Catalana per a la Recerca i la Innovació. Barcelona, pp. 295-460.

GOETGELUK, R., KAUKO, T. y PRIEMUS, H. (2005): «Can Red Pay for Blue? Methods to Estimate the Added Value of Water in Residential Environments», en Journal of Environmental Planning and Management, $\mathrm{n}^{\circ}$ 48(1), pp. 103-120.

GÓMEZ MENDOZA, J. (1977): Agricultura y expansión urbana. La campiña del bajo Henares en la aglomeración de Madrid. Alianza. Madrid, 352 pp.

GRIGG, D. (1995): An introduction to agricultural geography. Routledge. London/New York, $217 \mathrm{pp}$.

GUAL, V. (2008): «El punt de partida de l'agricultura moderna. De la Sentència Arbitral de Guadalupe i les Germanies a la crisi de finals del cinc-cents». En: E. Serra (Coord.), Història Agrària dels Països Catalans. Edat Moderna. Fundació Catalana per a la Recerca i la Innovació. Barcelona, pp. 13-30.

HAGGETT, P., CLIFF, A.D. y FREY, A. (1977): Locational analysis in human geography. Edward Arnold. London, 605 pp.

HOUSTON, P. (2005): «Re-valuing the Fringe: Some Findings on the Value of Agricultural Production in Australia's Peri-Urban Regions», en Geographical Research, $\mathrm{n}^{\circ}$ 43(2), pp. 209-222.

IBÀÑEZ, J.J. (2004): «Les dades bàsiques dels boscos a Catalunya». En: J. Terradas y F. Rodà (Dirs.), Els boscos de Catalunya. Estructura, dinàmica i funcionament. Generalitat de Catalunya. Barcelona, pp. 28-42. 
IGLÉSIES, J. (1968): La crisi agrària de 1879-1900: la fil·loxera a Catalunya. Edicions 62. Barcelona, $289 \mathrm{pp}$.

IOFFE, G. y NEFEDOVA, T. (2001): «Land use changes in the environs of Moscow», en Area, $\mathrm{n}^{\mathrm{O}} 33(3)$, pp. 273-286.

JUILLARD, É. (1961): «L'urbanisation des campagnes en Europe occidentale», en Études rurales, $\mathrm{n}^{\circ} 1$, pp. 18-33.

LLENSÁ, S. (1951): Breve historia de las medidas agrarias de la antigüedad y estudio particular de aquellas cuyo uso es tradicional en Cataluña. Cámara Oficial Sindical Agraria de Barcelona. Barcelona, 128 pp.

LLEONART, P., MACIAS, P. y ARDÈVOL, R. (1981): El Maresme: les claus de la seva contínua transformació. Banca Catalana. Barcelona, 383 pp.

LLOBET, S. (1947): El medio y la vida en el Montseny. Consejo Superior de Investigaciones Científicas. Barcelona, 518 pp. Reedición en catalán: LLOBET, S. (1990): El medi i la vida al Montseny. Estudi geogràfic. Museu de Granollers/Agrupació Excursionista de Granollers. Granollers, 486 pp.

LLOBET, S. (1955a): «De geografía agraria de la comarca del Maresme (Barcelona) (1)», en Estudios geográficos, $\mathrm{n}^{\circ}$ 58, pp. 23-72.

LLOBET, S. (1955b): «De geografía agraria de la comarca del Maresme (Barcelona) (2)», en Estudios geográficos, $\mathrm{n}^{\circ}$ 59, pp. 215-297.

LLOBET, S. (1959): «La industria del vino espumoso español», en Estudios geográficos, $\mathrm{n}^{\mathrm{o}} 77$, pp. 459-481.

LLOBET, S. (1968): «El Vallès». En: L. Solé (Dir.) (1958-1968), Geografia de Catalunya. Aedos. Barcelona, vol. III, pp. 363-404.

LLOVET, J. (1948): «Contribución al estudio general de la agricultura en la provincia de Barcelona», en Anales de la Escuela de Peritos Agrícolas, $\mathrm{n}^{\circ}$ 7, pp. 3-85.

LÓPEZ ONTIVEROS, A. (1971): «Notas sobre el catastro actual como fuente geográfica», en Estudios geográficos, no 122 , pp. 119-143.

LÓPEZ ONTIVEROS, A. (2003): «Descubrimiento, conformación histórica y problemática de los paisajes rurales». Fundación Duques de Soria. Soria, 17 pp. Ponencia inédita presentada en el Seminario «Naturaleza y cultura del paisaje», parcialmente publicada en: LÓPEZ ONTIVEROS, A. (2004): «Descubrimiento y conformación histórica de los paisajes rurales». En: N. Ortega Cantero (Ed.), Naturaleza y cultura del paisaje. Fundación Duques de Soria/Universidad Autónoma de Madrid. Soria/ Madrid, pp. 123-148.

MAJORAL, R. (1979): La utilización del suelo agrícola en Catalunya. Universitat de Barcelona. Barcelona, 505 pp. Tesis doctoral inédita.

MAJORAL, R. (1997): «Socioestructuras agrarias en España. Un análisis regional». En: V. Bretón, F. García Pascual y J.J. Mateu (Coords.), La agricultura familiar en España. Estrategias adaptativas y políticas agropecuarias. Universitat de Lleida. Lleida, pp. 45-82.

MAJORAL, R. (2006): «De la guerra civil a la Unió Europea». En: R. Garrabou (Coord.), Història Agrària dels Països Catalans. Segles XIX-XX. Fundació Catalana per a la Recerca i la Innovació. Barcelona, pp. 605-651.

MAJORAL, R. (Coord.) (2002): Cataluña. Un análisis territorial. Ariel. Barcelona, 447 pp.

MARTÍN, M. (1999): El Rec Comtal (1822-1879). La lluita per l'aigua a la Barcelona del segle XIX. Fundació Salvador Vives i Casajuana. Barcelona, 229 pp.

MAZUREK, H. y BLANCHEMANCHE, P. (1992): «La organización del paisaje rural mediterráneo de los pueblos a las fincas de pastoreo». En: Paisaje mediterráneo. Electa. Milano, pp. 142-153.

MEYNIER, A. (1959). Les paysages agraires. Armand Colin. Paris, 192 pp. 
MIR, R.M. (1943): Cataluña agrícola: aportación a su estudio. Ediciones Técnico-publicitarias. Barcelona, 462 pp.

MOLINERO, F. et al. (Eds.) (2004): Atlas de la España Rural. Ministerio de Agricultura, Pesca y Alimentación. Madrid, $463 \mathrm{pp}$.

MOLLEVÍ, G. (2007): La geografía de la vid y el vino en Cataluña. Davinci. Barcelona, 225 pp.

MURO, J.I., NADAL, F. y URTEAGA, L. (1996): Geografía, estadística y catastro en España 1856-1870. Serbal. Barcelona, 275 pp.

NADAL, F. (2007): «Els atles parcel-laris municipals de la província de Barcelona (18511882)». En: La cartografia cadastral a Espanya (segles XVIII-XIX). Institut Cartogràfic de Catalunya. Barcelona, pp. 95-106.

NADAL, F. y URTEAGA, L. (2008): «L'impacte geogràfic de la plaga de l'oïdi sobre el vinyar català: el cas de la comarca del Maresme (1852-1862)», en Cuadernos de Geografía, n 83, pp. 39-59.

NADAL, F., URTEAGA, L. y MURO, J.I. (2005): «La documentación cartográfica de la contribución de inmuebles, cultivo y ganadería: el caso de la provincia de Barcelona (1845-1895)», en Boletín de la Asociación de Geógrafos Españoles, nº 40, pp. 83-109.

NEL·LO, O. (2001): Ciutat de ciutats. Reflexions sobre el procés d'urbanització a Catalunya. Empúries. Barcelona, 239 pp.

NOGUÉ, J. (2003): «Lugares vacíos, paisajes ignorados», en La Vanguardia, 26-2-2003, pp. 22-23.

OCDE (1979): L'agriculture dans l'aménagement des aires péri-urbaines. Organisation de Coopération et de Développement Économiques. Paris, 104 pp.

PAÜL, V. (2006): L'ordenació dels espais agraris metropolitans. Plans, gestió i conflictes territorials a la regió de Barcelona. Universitat de Barcelona. Barcelona, 1138 pp. Tesis doctoral inédita.

PAÜL, V. (2009): «L'ordenació dels espais agraris a Catalunya. Una visió retrospectiva». En: S. Callau et al. (Eds.), La futura llei d'espais agraris de Catalunya. Documenta Universitaria. Girona, pp. 39-84.

PAÜL, V. (2011): «Los viñedos de Alella: de terruño de un vino privilegiado a paisaje de identidad». En: F. Molinero, J. Tort y J. Ojeda (Eds.), Los paisajes agrarios de España. Caracterización, evolución y tipificación. Ministerio de Medio Ambiente y Medio Rural y Marino. Madrid, pp. 382-394.

PAÜL, V. y MCKENZIE, F. (2010): «Agricultural Areas Under Metropolitan Threats: Lessons for Perth from Barcelona». En: G.W. Luck, D. Race y R. Black (Eds.), Demographic Change in Australia's Rural Landscapes. Implications for Society and the Environment. Springer. Dordrecht, pp. 125-152.

PAÜL, V. y SERRANO, D. (2005): Muntanyes d'Ordal. El nom que no surt als mapes. Publicacions de l'Abadia de Montserrat. Barcelona, 120 pp.

PAÜL, V. y TONTS, M. (2005): «Containing Urban Sprawl: Trends in Land Use and Spatial Planning in the Metropolitan Region of Barcelona», en Journal of Environmental Planning and Management, $\mathrm{n}^{\circ}$ 48(1), pp. 7-35.

PEIX, J. (2009): «La agricultura periurbana de la región metropolitana de Barcelona». En: Ò. Alfranca y M. Pujolà (Eds.), Agricultura periurbana. Universitat Politècnica de Catalunya. Barcelona, pp. 15-39.

PÉREZ MOLINA, I. (1990): «L'agricultura a l'Hospitalet segons el Cadastre de 1718», en Manuscrits. Revista d'Història Moderna, no 8, pp. 237-253.

PÉREZ PICAZO, M.T. (1998): «Fuentes fiscales e historia agraria. El debate en torno a las posibilidades heurísticas de los amillaramientos», en Estudios geográficos, $\mathrm{n}^{\circ} 231$, pp. 285-310. 
PINYOT, J. (1985): El Reial Cadastre de Castellar del Vallès. Arxiu d'Història de Castellar. Castellar del Vallès, $167 \mathrm{pp}$.

PIQUERAS, J. (2005): «La filoxera en España y su difusión espacial», en Cuadernos de Geografía, no 77, pp. 101-136.

PLANAS, J. (2007): «La vinya al Vallès: una perspectiva històrica», en Notes. Centre d'Estudis Molletans, $\mathrm{n}^{\circ}$ 22, pp. 83-103.

POMÉS, J. (1991): Les «Mataró's potatoes» $i$ el cooperativisme agrari al Maresme: 1903-1939. La Federació de Sindicats Agrícoles del Litoral. Caixa d'Estalvis Laietana. Mataró, $231 \mathrm{pp}$.

POMÉS, J. y BARRIENDOS, M. (2002): El Pantà de Foix. Història i evolució de l'entorn immediat. Fundació Castellet del Foix. Barcelona, 174 pp.

PREVOSTI, M. (2005): «L'agricultura en el món romà». En: J. Guitart (Coord.), Història Agrària dels Països Catalans. Antiguitat. Fundació Catalana per a la Recerca i la Innovació. Barcelona, pp. 293-343.

PUJOL, J. y BENELBAS, L. (1989): «L'agricultura». En: J. Nadal (Dir.), Història econòmica de la Catalunya contemporània. Enciclopèdia Catalana. Barcelona, vol. 5, pp. 129-208.

RÀFOLS, J. (2000): «La innovación tecnológica como factor de reubicación de la producción láctea», en Scripta Nova. Revista Electrónica de Geografía y Ciencias Sociales, n 69(14), 14 pp. Disponible en: <http://www.ub.edu/geocrit/sn-69-14.htm> (Acceso 20-7-2011).

ROBINSON, G.M. (2004): Geographies of Agriculture. Globalisation, Restructuring and Sustainability. Pearson. London, 309 pp.

ROSÉS, J. (Dir.) (1989): El Maresme. Diversificació econòmica i aprofitament intensiu del territori. Caixa d'Estalvis de Catalunya. Barcelona, $451 \mathrm{pp}$.

SAITO, Y. y TAKENAKA, K. (2004): «Development of wine industry in Spain: three pioneer regions in commercial wine production», en Geographical Review of Japan, $\mathrm{n}^{\mathrm{o}}$ 77(5), pp. 19-39.

SANS, J. y HARO, A. de (2000): «El plànol parcel-lari de Sant Boi de Llobregat de 1861 i els usos del sòl agrícola. Un estudi aproximatiu», en Treballs de la Societat Catalana de Geografia, $\mathrm{n}^{\circ}$ 49, pp. 129-143.

SANZ, F. (1975): El viñedo español. Ministerio de Agricultura. Madrid, 278 pp.

SEGURA, A. (Coord.) (1988): El Catastro en España. 1714-1906. Lunwerg/Ministerio de Economía y Hacienda. Barcelona/Madrid, 193 pp.

SEGURA, A. y SUAU, J. (1984): «L'evolució de l'estructura de la propietat de la terra al Pla de Barcelona. 1723-1823/1841». En: El Pla de Barcelona i la seva història. La Magrana/Ajuntament de Barcelona. Barcelona, pp. 299-324.

SERRATOSA, A. (1979): Objetivos y metodología de un plan metropolitano. Oikos-tau. Vilassar de Mar, $352 \mathrm{pp}$.

SOLANS, J.A. (2002): «L'ocupació del sòl en el sistema metropolità central durant el període 1980-1998», en Papers. Regió Metropolitana de Barcelona, $\mathrm{n}^{\circ}$ 36, pp. 49-72.

TELLO, E. (1999): «La formación histórica de los paisajes agrarios mediterráneos: una aproximación coevolutiva», en Historia Agraria, nº 19, pp. 195-211.

TELLO, E. y GARRABOU, R. (2007): «La evolución histórica de los paisajes mediterráneos: algunos ejemplos y propuestas para su estudio». En: V. Paül y J. Tort (Eds.), Territorios, paisajes y lugares. Trabajos recientes de pensamiento geográfico. Galerada/ Asociación de Geógrafos Españoles. Cabrera de Mar/Madrid, pp. 19-63.

THOMAS, J.K. y HOWELL, F.M. (2003): «Metropolitan Proximity and U.S. Agricultural Productivity, 1978-1997», en Rural Sociology, nº 68(3), pp. 366-386.

TORT, J. y PAÜL, V. (2009): «El paisatge del Pla de Barcelona». En: Masies de Barcelona. Angle/Ajuntament de Barcelona. Manresa/Barcelona, pp. 14-59. 
TRIBÓ, G. (1995): «Burgesia barcelonina i gran propietat al Baix Llobregat (1850-1930)». En: À. Calvo (Ed.), El pas de la societat agrària a industrial al Baix Llobregat. Agricultura intensiva i industrialització. Publicacions de l'Abadia de Montserrat. Barcelona, pp. 149-178.

TRIBÓ, G. (2005): «Expansió del regadiu, un impuls definitiu a la intensificació agrícola (finals del segle xvIII-1930). Demografia, agricultura i industrialització al Baix Llobregat». En: N. Prat y E. Tello (Dirs.), El Baix Llobregat: història i actualitat ambiental d'un riu. Centre d'Estudis Comarcals del Baix Llobregat. Sant Feliu de Llobregat, pp. 172-193.

VALLS, F. (2003): «L'aiguardent, el vi i els mercats de la viticultura penedesenca durant el segle XVIII i la primera meitat del XIX». En: J. Colomé (Coord.), De l'aiguardent al cava. El procés d'especialització vitivinícola a les comarques del Penedès-Garraf. El 3 de Vuit. Vilafranca del Penedès, pp. 75-94.

VENDRANES, G. y RULLIER, C. (1996): Oli d'Olesa. La passió d'un poble. Publicacions de l'Abadia de Montserrat. Barcelona, 211 pp.

VILA, P. (1930): «El Vallès. Assaig geogràfic». En: Comarca del Vallès. Casa del Vallès. Barcelona, vol. I, pp. 1-83.

VILAR, P. (1962): La Catalogne dans l'Espagne moderne. Recherches sur les fondements économiques des structures nationales. SEVPEN. Paris, 3 vol.

ZAMORA, F. (1785-1789): Diario de los viajes hechos en Cataluña. Texto inédito en origen. Edición: BOIXAREU, R. (Ed.) (1973): «Diario de los viajes hechos en Cataluña» de Francisco de Zamora seguit de la resposta del corregiment de Barcelona al seu qüestionari feta per Josep Albert Navarro-Mas i Marquet. Curial. Barcelona, 510 pp. 